\title{
DIVERSIDADE GENÉTICA DE Myrciaria floribunda (West ex Willdenow) Berg (CAMBUÍ) EM PAISAGEM FRAGMENTADA DA SERRA DA MANTIQUEIRA, MG
}

\section{GIULIANA MARA PATRÍCIO VASCONCELOS}

Dissertação apresentada à Escola Superior de Agricultura "Luiz de Queiroz", Universidade de São Paulo, para obtenção do título de Mestre em Recursos Florestais, com opção em Conservação de Ecossistemas Florestais.

\author{
PIR A C I C A B A \\ Estado de São Paulo - Brasil \\ Abril-2002
}




\title{
DIVERSIDADE GENÉTICA DE Myrciaria floribunda (West ex Willdenow) Berg (CAMBUÍ) EM PAISAGEM FRAGMENTADA DA SERRA DA MANTIQUEIRA, MG
}

\section{GIULIANA MARA PATRÍCIO VASCONCELOS}

Engenheira Florestal

Orientador: Prof. Dr. WEBER ANTÔNIO NEVES AMARAL

\begin{abstract}
Dissertação apresentada à Escola Superior de Agricultura "Luiz de Queiroz", Universidade de São Paulo, para obtenção do título de Mestre em Recursos Florestais, com opção em Conservação de Ecossistemas Florestais.
\end{abstract}

P I R A C I C A B A

Estado de São Paulo - Brasil

Abril-2002 
Dados I nt ernaci onai s de Cat al ogação na Publ i cação ( $\mathrm{Cl} P$ ) DI VI SÃo DE BI BLI OTECA E DOCUMENTAÇÃo - ESALQ/ USP

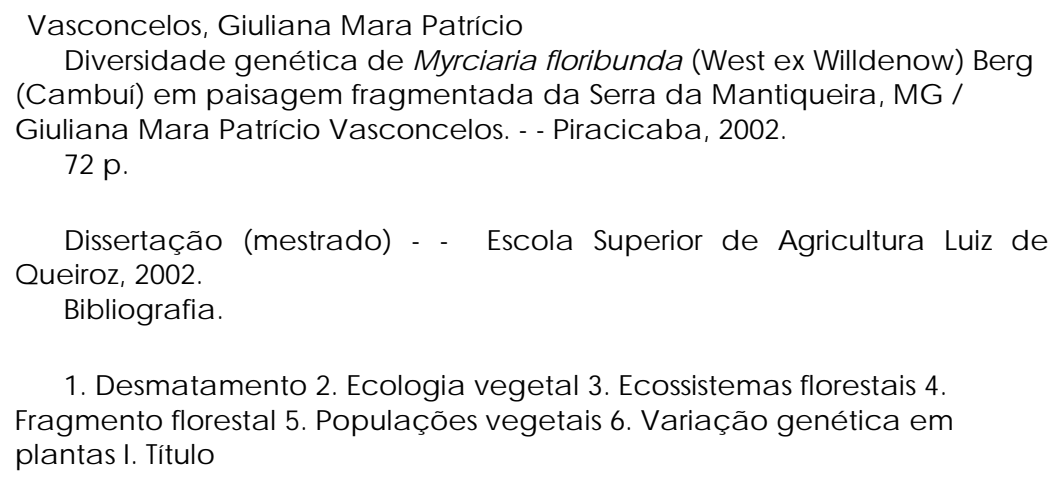

1. Desma tamento 2. Ec ologia vegetal 3. Ec ossistema floresta is 4. Fragmento florestal 5. Populações vegeta is 6 . Va ria ção genética em plantas I. Título

CDD 634.94

\section{"Permitida a cópia total ou parcial deste documento, desde que citada a fonte - $\mathrm{O}$ autor"}


Dedico este trabalho ao ... "Senhor Deus que do solo fez brotar toda sorte de árvores agradáveis à vista e boas para alimento ..." (Gn.2:9) 


\section{AGRADECIMENTOS}

Ao Deus Triúno por ter se tornado o Espírito, tão acessível e vir habitar em meu espírito, capacitando-me assim a todas as coisas, principalmente a concluir este trabalho.

Ao curso de pós-graduação em Recursos Florestais da ESALQ/USP, pela oportunidade de realização do Mestrado, e à Coordenadoria de Aperfeiçoamento de Pessoal de Nível Superior (CAPES), pela bolsa de estudos.

Ao Prof. Weber A. N. Amaral, pela orientação, amizade, apoio e por ter me dado esta oportunidade de trabalharmos juntos.

À Profa. Edivani V. Franceschinelli, também pela orientação, apoio no laboratório, convivência e amizade em todos os momentos, incentivando-me sempre a prosseguir.

Ao Ministério do Meio Ambiente e ao Projeto de Conservação e Utilização Sustentável da Diversidade Biológica Brasileira (PROBIO), que financiou as viagens de campo, material de laboratório e regentes, sem os quais este trabalho não poderia ter sido realizado.

Ao Departamento de Botânica, representado pelo Prof. João Renato e Laboratório de Biologia de Populações de Plantas da UFMG, por ter me acolhido na fase das análises.

À Profa. Bernadete, Profa. Dolores, Rosângela, Renata e Marlene pelo treinamento no início do trabalho, pelas dicas e ajuda no desenvolver das atividades.

À Profa. Dulcinéia Carvalho e ao Prof. Sebastião Rosado, pela oportunidade e ensinamentos na iniciação científica, que foram muito úteis no dia-a-dia do laboratório neste mestrado. incentivo.

Ao Prof. Natal pelo apoio no início do curso, conselhos e conversas de

À Margarete e Alexandre da secretaria de PG, agradeço a atenção, paciência e simpatia.

Aos moradores e proprietários dos fragmentos estudados (Tião Loriano, Zé Tostãozinho, Zé Maria e Altair), por permitir o acesso aos fragmentos e a coleta de material.

Aos amigos, Toninho, Márcio, João, Rose, Virgínia, Jacqueline, Marcela e Bruno pela ajuda na coleta de campo, atividades de laboratório, extração e tantas outras coisas mais, que nem dá para citar aqui, sou muito grata. 
Ao amigo Luciano Arruda Ribas, pelas dicas de laboratório, definição de protocolo e leitura dos géis. À Milene e Maria Beatriz Perecin pelos comentários na qualificação.

À Dênmora, Piedade, Veridiana, Patrícia, Viviane, Glaucia e Ana pela convivência, trocas de experiências e amizade.

Ao Moisés, Sueli, Anderson e Alencar pelo carinho e hospitalidade no início do curso.

Ao Luís, Raquel, Esdras e Davi pelo carinho e hospitalidade no início e final do curso.

À Eliana, Isabel, Mediam e Nankoua pelas orações e companheirismo em todos os momentos.

Aos jovens da UFMG, pelas reuniões tão desfrutáveis no campus, que sempre me faziam lembrar o verdadeiro motivo de estarmos ali.

Ao meu GFCM "querido", sou grata pelas orações e pelo cuidado prático e amoroso.

E finalmente e principalmente à minha família, pais, irmãos, sobrinhos, cunhada, avós, tios, primos, que tanto amo, apesar de toda distância nesses últimos anos e todos momentos sacrificados, obrigada pela compreensão e apoio. E também minha família espiritual, aos irmãos de Lavras, Piracicaba e Belo Horizonte, que vivem comigo a Vida da Igreja, sou grata a cada um pelo Cristo que há em vocês e que de alguma forma me sustentou neste período, que não foi fácil, o Senhor sabe de todas as coisas. 


\section{SUMÁRIO}

Página

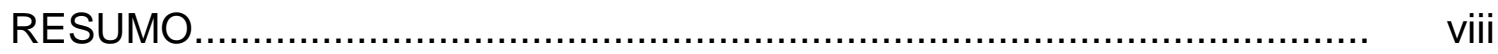

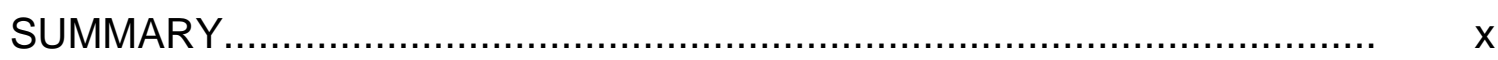

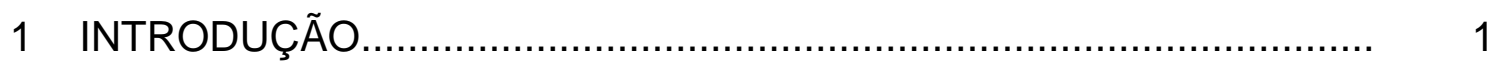

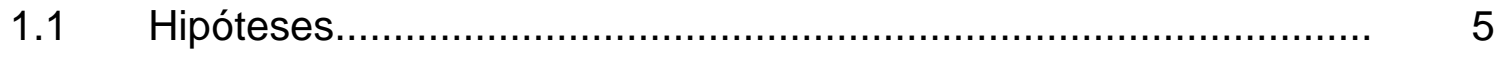

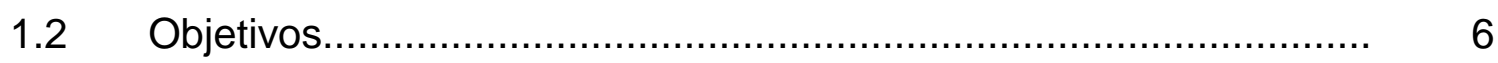

2 REVISÃO DE LITERATURA............................................................

2.1 Diversidade e estrutura genética de populações naturais................ 7

2.1.1 Técnicas para o estudo da diversidade genética...................... 8

2.2 Processos de fragmentação...................................................... 10

2.3 Efeito da fragmentação na genética de população de planta.......... 12

2.4 Myrciaria floribunda (West ex Willdenow) Berg (cambuí)...................... 15

3 MATERIAL E MÉTODOS............................................................ 16

3.1 Local de estudo................................................................ 16

3.1.1 Histórico de fragmentação........................................................... 17

3.1.2 Descrição dos fragmentos................................................... 20

3.2 Seleção da espécie................................................................ 22

3.3 Coleta, transporte e armazenamento das folhas de cambuí........... 22

3.4 Análises eletroforéticas............................................................ 23 


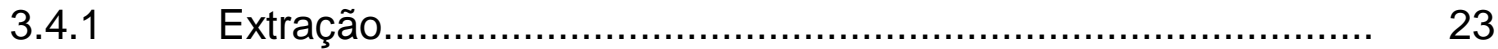

3.4.2 Tampões de eletrodo/gel e sistemas enzimáticos.................... 24

3.4.3 Condições de corrida.............................................................. 25

3.4.4 Leitura e interpretação dos zimogramas................................ 26

3.5 Metodologia estatística........................................................ 26

3.5.1 Variabilidade genética........................................................ 26

3.5.2 Estrutura genética....................................................... 29

3.5.3 Fluxo gênico............................................................. 29

3.5.4 Tamanho efetivo populacional............................................. 30

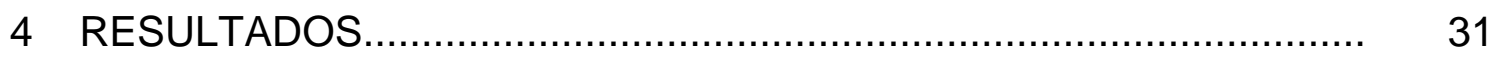

4.1 Interpretação genética dos sistemas enzimáticos.......................... 31

$4.2 \quad$ Diversidade genética.............................................................. 33

4.3 Estrutura genética................................................................... 33

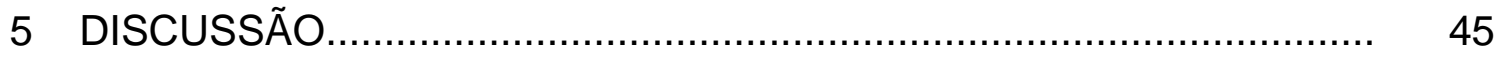

$5.1 \quad$ Diversidade genética.......................................................... 45

$5.2 \quad$ Estrutura genética.............................................................. 48

5.3 Biologia da espécie e conservação da diversidade genética.......... 49

6 CONCLUSÕES........................................................................ 52

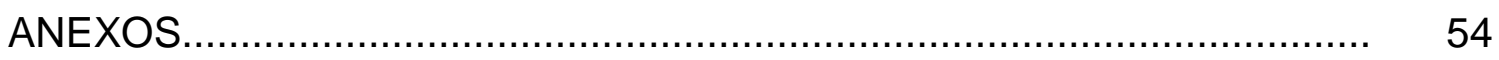

REFERÊNCIAS BIBLIOGRÁFICAS................................................... 61 


\section{DIVERSIDADE GENÉTICA DE Myrciaria floribunda (WEST EX WILLDENOW) BERG (CAMBUÍ) EM PAISAGENS FRAGMENTADAS DA SERRA DA MANTIQUEIRA, MG.}

Autora: Giuliana Mara Patrício Vasconcelos

Orientador: Weber Antônio Neves do Amaral

\section{RESUMO}

Este trabalho diz respeito à diversidade genética de Myrciaria floribunda (West ex Willdenow) Berg (cambuí), uma espécie arbórea de sub-bosque, em paisagem fragmentada da Serra da Mantiqueira, MG. A diversidade genética foi estudada a partir dos dados de análises eletroforéticas de isoenzimas. Foram coletadas folhas de indivíduos jovens em duas populações dentro de um fragmento controle (5810,27 ha) e em dois fragmentos menores (18 e $10 \mathrm{ha}$ ), sendo quarenta plantas por fragmento. Através da análise de sete locos isoenzimáticos foi avaliada o número médio de alelos por loco $(\hat{A})$, número médio de alelos por loco polimórfico $\left(\hat{A}_{p}\right)$, porcentagem de locos polimórficos $(\hat{P})$, heterozigosidade média esperada $\left(\hat{H}_{e}\right)$, heterozigosidade observada $\left(\hat{H}_{o}\right)$ e freqüências alélicas, utilizando-se alelos de baixa freqüência. A heterozigosidade observada para os quatro fragmentos foi elevada (entre 0,288 a 0,386$)$. A variação genética intrapopulacional, avaliada pela riqueza alélica foi menor nos fragmentos menores que nas populações contida no fragmento 
controle. Alguns alelos encontrados em menor freqüência no fragmento controle tiveram suas freqüências reduzidas nos fragmentos menores, sendo que um alelo foi perdido nos fragmentos menores, provavelmente devido à redução do tamanho populacional durante a fragmentação, ou à deriva genética após a fragmentação ou a amostragem realizada. $O$ índice de diversidade gênica de Nei (heterozigosidade esperada) não foi muito diferente entre as quatro populações, apesar de mostrar uma tendência à diminuição nos fragmentos menores. Os indivíduos jovens analisados apresentaram valores de $\hat{f}=$ 0,0864, sugerindo que estas populações tem vindo de cruzamentos panmíticos, provavelmente anteriores ao processo de fragmentação. Estas quatro populações apresentaram pequena diferenciação genética entre elas $\left(\hat{\boldsymbol{\theta}}_{p}=\right.$ 0,0555), o número estimado de migrantes foi relativamente alto $\left(N_{m}=4,25\right)$. Este trabalho desta forma não foi capaz de detectar o efeito da fragmentação na endogamia desta espécie. 


\title{
GENETIC DIVERSITY OF Myrciaria floribunda (WEST EX WILLDENOW) BERG (CAMBUÍ) IN FRAGMENTED LANDSCAPES OF THE MANTIQUEIRA HILLS, MG
}

\author{
Author: Giuliana Mara Patrício Vasconcelos \\ Adviser: Weber Antônio Neves do Amaral
}

\section{SUMMARY}

This research is about effects of forest fragmentation on the genetic diversity of Myrciaria floribunda (West ex Willdenow) Berg (cambuí), a tropical tree species from the Atlantic Forest (Mantiqueira hills), State of Minas Gerais. This work is about genetic diversity studies of de Myrciaria floribunda (cambuí), a late successional species from fragmented landscapes of the Mantiqueira hills. Genetic diversity was assessed using electrophoresis of isozymes. Leaves from juveniles trees were collected from four populations, two within a control fragment (5810,27 ha) and from two other small fragments (18 e $10 \mathrm{ha})$. Forty plants were sampled per populations. Seven loci were studied regarding the average number of alleles per locus $(\hat{A})$, the average number of alleles per polymorphic loci $\left(\hat{A}_{\mathrm{p}}\right)$, percentage of polymorphic loci $(\hat{P})$, expected $\left(\hat{H}_{e}\right)$ and observed heretozigosity $\left(\hat{H}_{o}\right)$, and allelic frequency, using alleles of low frequency. The observed heterozigosity was high for all fragments (from 0,288 to 0,386 ). Within population genetic diversity, measured by allelic richness was 
lower in small fragments compared with the large fragment. Low frequency alleles found in the large fragment showed an even lower frequencies in the two small fragments. One allele was lost in the small fragments, probably due to a reduction in population size because of the fragmentation process, and probably due to genetic drift or sampling strategy. Nei's diversity index (expected heterozigosity) did not differ among populations, although lower in the small fragments. The result for $\hat{f}=0,0864$ indicated that the current populations probably were originated from panmmitic populations, established before the fragmentation process. Little genetic differentiation was detected among populations $\left(\hat{\boldsymbol{\theta}}_{p}=0,0555\right)$, however the number of migrants was considerably high $\left(N_{m}=4,25\right)$. Therefore this work was not able to detect the effects of endogamy due to the forest fragmentation on the studied species. 


\section{INTRODUÇÃO}

O processo de substituição da cobertura florestal, devido ao desmatamento, à expansão das fronteiras agrícolas e pecuárias, à exploração de espécies arbóreas nativas e ao crescimento urbano, têm ocasionado na Mata Atlântica e particularmente no estado de Minas Gerais, a fragmentação dos ecossistemas florestais, limitando-os a pequenas manchas ou fragmentos isolados. A cobertura florestal natural de Mata Atlântica do Estado de Minas Gerais ocupa atualmente apenas $4 \%$ de sua área original (Fundação SOS Mata Atlântica et al., 1998).

Apesar da Serra da Mantiqueira ser uma área da Mata Atlântica muito importante como corredor ecológico, com alta biodiversidade e elevado grau de endemismo, muito pouco se conhece de sua flora ou fauna. Além disso, uma extensa área de mata já foi devastada, e hoje, no sul de Minas, os maiores fragmentos ocupam principalmente altas altitudes da Serra da Mantiqueira (Franceschinelli, 2001).

De acordo com Várzea (1942), a Mantiqueira estende-se da margem norte do Tietê, onde se localiza o Pico do Jaraguá, Estado de São Paulo até o sul da Bahia, onde se encontra o morro do descobrimento. Já Mendes Júnior et al. (1991), consideram a Serra da Mantiqueira como um conjunto orográfico com extensão e limites nem sempre bem definidos, que se estende por três estados do sudeste brasileiro: Minas Gerais (MG), São Paulo (SP) e Rio de

Janeiro (RJ). O termo Mantiqueira teria como provável significado "local de precipitações abundantes" ou "local em que se originam as águas". 
Os remanescentes da formação florestal característica dessa região são de grande valor ecológico e taxonômico, e a diversidade genética existente nestes remanescentes, representa um banco vivo de informações sobre a estrutura e o funcionamento deste tipo de Floresta Ombrófila Mista AltiMontana. O reconhecimento da importância deste ecossistema pode ser medido pelos inúmeros trabalhos que vêm sendo realizados na área (Amaral, 2001) e por ter sido considerada recentemente como área prioritária para proteção de mananciais e de importância biológica especial (Biodiversitas, 1998).

Meirelles (1991) considera que a Serra da Mantiqueira é uma das maiores cadeias de montanhas do leste sul-americano, conservando-se como um museu vivo, de alta diversidade de fauna e flora, apesar de estar encravada no triângulo de maior concentração industrial e urbana do país (SP, MG e RJ).

Com a duplicação da rodovia Fernão Dias, que liga Belo Horizonte à São Paulo, houve a necessidade de disciplinar o uso dos recursos hídricos, energéticos e naturais, implantando a Área de Proteção Ambiental (APA) Fernão Dias, que abrange toda a bacia do Rio Camanducaia e parte da bacia do Rio Jaguari. As nascentes do Camanducaia localizam-se no próprio município, sendo este rio um dos afluentes do Rio Jaguari, o qual por sua vez, faz parte da bacia do Rio Piracicaba. O Rio Jaguari, em território paulista, faz parte do Sistema Cantareira, que foi projetado para permitir a reversão de água à bacia do Alto Tietê, sendo responsável por 36\% (em média) do abastecimento da Grande São Paulo (Aguari, 2001).

Segundo o Consórcio Figueiredo Ferraz (1999), a atuação antrópica limitou a área coberta por florestas naturais a apenas 7\% da área da Unidade de Gerenciamento de Recursos Hídricos - Piracicaba/Capivari/Jundiaí (UGRHIPCJ). E hoje as porções de florestas situam-se principalmente junto às cabeceiras dos maiores rios (Jaguari, Atibaia, Camanducaia, Corumbataí e Jundiaí). As florestas tem importância na proteção do solo, dificultando processos erosivos do solo, na conservação dos recursos hídricos e na sua 
conformação enquanto habitats naturais para a fauna, os remanescentes de cobertura florestal da região em estudo constituem um indicador fundamental de qualidade de ambiente. Segundo Poggiani \& Oliveira (1999), áreas remanescentes de vegetação nativa são importantes como fonte de propágulos, habitat para polinizadores e dispersores, para a manutenção da biodiversidade e para a sustentabilidade das populações naturais ao longo do tempo. Portanto para proteger estas nascentes, os rios que cortam a região, e a sua biodiversidade é necessário que se protejam os fragmentos das áreas vegetadas que ainda existem, em especial as matas ciliares.

Com o intuito de se ter um estudo da biodiversidade e fornecer subsídios para um programa de conservação e recuperação dos fragmentos florestais da APA Fernão Dias, foi iniciado um projeto financiado pelo PROBIO (Projeto de Conservação e Utilização Sustentável da Diversidade Biológica Brasileira) do Ministério do Meio Ambiente em 1998, do qual este faz parte como um subprojeto. Para este estudo foi selecionado fragmentos inseridos na APA Fernão Dias e bacia do Rio Camanducaia, os quais como já foi citado acima, são importantes para produção de serviços ambientais e conservação da biodiversidade. Alguns fragmentos florestais se encontram bem preservados e outros estão em estado de degradação acelerado e podem desaparecer dentro de algumas décadas. Para evitar tal situação, não só a proteção destas áreas vegetadas é importante, mas também a recuperação das mesmas. Deste modo, o estudo dos fragmentos ainda existente, ajuda definir estratégias de conservação e de uso sustentado dos recursos naturais (Meffe \& Carroll, 1994).

Apesar do processo de fragmentação florestal ser bem antigo no Brasil, os estudos do comportamento das espécies, fluxo gênico, migração e extinção são recentes. É recomendável conhecer como está a variabilidade genética existente nas espécies que estão nos fragmentos, e saber se estão sofrendo um processo de erosão genética que poderá levar a um comprometimento de várias populações. Informações moleculares sobre a variabilidade e a estrutura genética de populações florestais podem auxiliar no esclarecimento da 
condução de programas de conservação genética, bem como sobre a avaliação de coleções de germoplasma (Newburry \& Ford-Lloyd, 1993).

A fragmentação é um processo de ruptura na continuidade de habitats naturais que muitas vezes ocasiona também ruptura dos fluxos gênicos entre populações presentes nesses habitats, levando a perda da variabilidade genética em muitas espécies, consequentemente uma limitação evolutiva (Barrett \& Kohn, 1991), ou seja, perda da capacidade reprodutiva, da resistência à doenças e da plasticidade das populações em se adaptarem às mudanças ambientais, tornando-as suscetíveis à extinção (Heywood \& Stuart, 1994).

A fragmentação de contínuos florestais expõe as populações a problemas ecológicos e genéticos causados pela endogamia e perda de variação por deriva genética. Estudos de variabilidade genética são desenvolvidos para conhecer o nível de variação genética dentro de populações ou espécies, e o modo como ela se distribui dentro e entre populações (Hamrick, 1983).

A estrutura genética de plantas apresenta níveis de variação genética entre e dentro de populações, os quais são mantidos em função de fatores como o sistema reprodutivo, fluxo gênico (depende do modo de dispersão de pólen e semente), níveis de endogamia, seleção natural, deriva genética, distribuição geográfica, entre outros (Hamrick, 1983 e Nason et al., 1997).

A variação genética intrapopulacional consiste da soma de todas as variações genéticas encontradas entre os indivíduos dentro da população. A estrutura genética populacional é definida como a distribuição dessa variação genética no tempo e no espaço (Hamrick \& Loveless, 1989). Esta variação geralmente é quantificada em termos de porcentagem de locos polimórficos $(P)$, número médio de alelos por locos $(A)$ e diversidade gênica $\left(H_{e}\right)$ (Young et al., 1996).

A variabilidade genética dentro de populações naturais pode ser avaliada a partir de técnicas bioquímicas, como isoenzimas. Apesar do desenvolvimento 
de técnicas moleculares oferecerem grande polimorfismo em nível de DNA, a eletroforese de isoenzimas ainda possui algumas vantagens na obtenção das estimativas de variabilidade genética e dos parâmetros que descrevem o sistema de cruzamento (Parker et al., 1998). Esta técnica tem mostrado ser eficiente para a caracterização da dinâmica da movimentação de alelos em populações naturais.

Neste trabalho foi abordado o estudo do efeito da fragmentação na variabilidade genética de Myrciaria floribunda (West ex Willdenow) Berg (cambuí), utilizando a eletroforese de isoenzimas, e sua distribuição entre e dentro de quatro populações naturais, duas populações se encontram dentro de um fragmento maior, denominado fragmento controle e duas populações em fragmentos menores.

\subsection{Hipóteses}

a) Considerando os dados de literatura, onde se observa, geralmente, um alto nível de diversidade genética para as espécies arbóreas tropicais, espera-se encontrar também alto nível de diversidade genética para Myrciaria floribunda (cambuí).

b) Como os indivíduos jovens devem estar sofrendo o efeito da fragmentação, espera-se encontrar nos fragmentos menores, que provavelmente contêm populações menores, níveis menores de variabilidade genética dentro da população, em comparação com as populações do fragmento controle, que contém uma população maior.

c) Encontrar baixa divergência genética entre as populações dentro do fragmento controle e talvez uma maior divergência entre as populações dos fragmentos menores. 


\subsection{Objetivos}

Investigar o efeito da fragmentação na diversidade genética de Myrciaria floribunda (cambuí), na Serra da Mantiqueira, APA Fernão Dias. Este estudo foi realizado em duas áreas dentro de um fragmento maior, denominado fragmento controle (5810.27 ha) e em dois fragmentos menores (18 e $10 \mathrm{ha}$ ), visando sua comparação.

Os objetivos específicos são:

a) Definir metodologia para a obtenção de marcadores isoenzimáticos.

b) Estimar a diversidade genética de Myrciaria floribunda (cambuí), em duas áreas dentro do fragmento controle e em dois fragmentos menores.

c) Verificar a distribuição da diversidade entre e dentro destas populações.

d) Verificar se ocorre fluxo gênico entre as populações de diferentes fragmentos e estimar a divergência genética entre estas populações em estudo. 


\section{REVISÃO DE LITERATURA}

\subsection{Diversidade e estrutura genética de populações naturais}

Segundo Hamrick \& Godt (1990), os estudos realizados com espécies arbóreas tropicais têm demonstrado que a história de vida e as características ecológicas das espécies refletem na variação intra e interpopulacional e na heterogeneidade de suas populações. De modo geral, as espécies arbóreas da floresta tropical, apresentam alta proporção de locos polimórficos e maior nível de diversidade genética dentro de populações que entre populações e o sistema de cruzamento é predominantemente misto. Hamrick \& Godt (1990), compilaram dados de isoenzimas em 653 trabalhos e demostraram que as plantas apresentam em média, cerca de 50,5\% dos locos polimórficos, 0,149 de heterozigosidade média esperada, 1,96 alelos por locos e divergência média $\left(\mathrm{G}_{\mathrm{ST}}\right)$ de $20 \%$ entre populações.

A extensão geográfica é considerado o principal fator relacionado à quantidade de variação genética dentro de espécies. $E$ tem sido observado que espécies de ampla distribuição geográfica, vida longa, com reprodução principalmente por fecundação cruzada (alógama) e dispersão de sementes por animais apresentam maiores níveis de variação genética que espécies com outras combinações de características (Hamrick \& Godt, 1989). Em nível populacional, a extensão geográfica e o sistema de cruzamento contribuem com a maior parte da variação genética encontrada dentro de populações. Espécies predominantemente alógamas apresentam maior variação genética dentro de suas populações que espécies autógamas (Hamrick \& Godt, 1989). 
Espécies de fecundação cruzada ou mista, com dispersão de pólen pelo vento, apresentam em média $10 \%$ da variação entre as populações, enquanto as espécies autógamas apresentam em média 51 \% da variação entre populações (Hamrick \& Godt, 1989).

A dispersão de pólen e sementes promovem o fluxo gênico nas plantas, que é um importante componente na estrutura genética das espécies, pois reduz a divergência genética entre populações (Nason et al., 1997). Segundo Wright (1943), populações separadas por longas distâncias e com limitado fluxo gênico podem tornar-se diferenciadas geneticamente uma das outras pelo processo de "isolamento por distância". Hamrick \& Loveless (1989), dizem que populações de espécies cuja polinização é feita por animais que percorrem longas distâncias, apresentam maior diversidade genética que aquelas polinizadas pelo vento ou animais que percorrem curtas distâncias, onde o fluxo gênico é limitado. Já a dispersão de sementes pelo vento ou por animais apresentam maior diversidade genética dentro das populações que a dispersão por barocoria.

\subsubsection{Técnicas para o estudo da diversidade genética}

Nei (1973) associou o conceito de diversidade à variação genética existente em uma dada espécie, sendo a heterozigosidade esperada a medida para quantificar esta diversidade.

A quantificação da diversidade pode ser feito através de vários marcadores morfológicos, fisiológicos, bioquímicos ou moleculares. Os primeiros marcadores utilizados foram os morfológicos, que representam variações fenotípicas de caráter mendeliano e um número reduzido de locos. No final da década de 60 os estudos de variação genética foram facilitados pelo desenvolvimento de marcadores isoenzimáticos e na década de 80 foram desenvolvidos os marcadores moleculares em nível de DNA. 
A eletroforese de isoenzimas, revelou uma nova fonte de marcadores genéticos capazes de identificar indivíduos homozigóticos e heterozigóticos. Esta técnica contribuiu para avanços expressivos na área da genética de populações, revelando uma quantidade significativa de variação nos mais diferentes organismos (Pinto et al., 2001).

Isoenzimas são as diferentes formas bioquímicas de uma enzima, com uma mesma especificidade de substrato, que podem ser identificadas por migração e coloração em gel. Podem ser controlados por um ou vários alelos situados num mesmo loco, ou em diferentes locos (Alfenas et al., 1991). Quando as enzimas são controladas por alelos de um único loco, elas são denominadas de aloenzimas Robinson, 1998). As isoenzimas são, em última análise, produto da expressão dos genes.

A simplicidade e rapidez da técnica, aliada ao seu baixo custo em relação aos marcadores baseados em polimorfismos de DNA, faz com que esse marcador continue a ser utilizado para responder às diversas perguntas que a pesquisa em Genética impõe.

A técnica de isoenzimas consiste de três etapas: extração das enzimas do tecido vegetativo, separação por eletroforese e coloração por métodos histoquímicos. Para a extração, as amostras são homogeneizadas, de preferência no gelo e na presença ou não de nitrogênio líquido, em soluções tampões contendo anti-oxidantes, estabilizadores osmóticos e agentes que atuam sobre fenóis, para preservar a atividade das enzimas.

A separação é feita com base na carga e no tamanho molecular. Após a separação, a visualização das isoenzimas é feita pela adição de um substrato específico que revela a atividade das enzimas, no gel, sob a forma de bandas. O padrão de bandas visualizado no gel constitui o fenótipo eletroforético, que é interpretado e deduzido seu genótipo. A população de indivíduos é então analisada em termos de locos e alelos, para cada sistema isoenzimático. Para a interpretação é necessário o conhecimento do número e tipo de cadeia polipeptídica que compõe a enzima (Pinto et al., 2001). 
A leitura dos fenótipos eletroforéticos permite avaliar a estrutura genética com base nas estimativas das freqüências alélicas e genotípicas, levando a conclusões sobre a magnitude e a distribuição da variabilidade entre e dentro das populações, conseqüências evolutivas, diferenciação geográfica de populações dentro de espécies, fluxo gênico, deriva genética e taxas de cruzamento.

A técnica de isoenzimas possui as seguintes vantagens: expressão codominante; padrão de herança mendeliana, ausência de pleiotropia e epistasia; fácil e rápida execução; indivíduos de qualquer estágio fenológico e em qualquer idade podem ser analisados e influência reduzida do meio. Como desvantagens: a técnica se limita às enzimas solúveis, e somente são detectadas as substituições de aminoácidos que resultam em diferenças na mobilidade da proteína durante a eletroforese; pequena amostragem de locos, comparando com os marcadores de DNA; alelos nulos, que controlam aloenzimas que não expressam atividade durante o processo de coloração, embora sejam raros, podem causar dificuldades na interpretação de zimogramas; custo e toxicidade dos reagentes, comparando com os marcadores morfológicos. Em espécies poliplóides, onde seu genes são representados por várias cópias, a interpretação adequada é dificultada , já que seus locos duplicados presentes nos diferentes genomas de uma espécie poliplóide podem apresentar alelos em comum (Alfenas, 1998).

\subsection{Processos de fragmentação}

O desmatamento ocasiona a fragmentação das florestas, que nada mais é que a transformação de uma grande extensão de habitats em numerosas manchas menores isoladas umas das outras, imersas em uma matriz circundante (Macedo, 1993; Young., 1996).

A fragmentação de habitats tornou-se um sério problema atual pois grande número de espécies está sendo perdido antes de se ter seu 
conhecimento. Para contornar esta situação são necessárias ações de manejo do ambiente para evitar a perda da diversidade biológica e de seus benefícios.

Viana (1995) diz que este processo de fragmentação deu origem a fragmentos florestais de diferentes áreas, formas, graus de isolamento, tipos de vizinhança e histórias de perturbação. Este autor define fragmento florestal como qualquer área de vegetação natural contínua, interrompida por barreiras antrópicas (estradas, culturas agrícolas, etc.) ou naturais (lagos, outras formações vegetais, etc.) capazes de diminuir significativamente o fluxo de animais, pólen e/ou sementes. O tamanho, forma, grau de isolamento, tipo de vizinhança e histórico de perturbações são fatores que afetam a diversidade biológica e a sustentabilidade dos fragmentos florestais (Viana, 1995).

Como principais conseqüências desta fragmentação, Viana (1990) descreve a diminuição da diversidade biológica, o distúrbio do regime hidrológico das bacias hidrográficas, as mudanças climáticas, a degradação dos recursos naturais e a deterioração da qualidade de vida das populações tradicionais. Com relação a diversidade biológica observa-se a extinção de espécies devido a: redução na diversidade e tamanho populacional das espécies animais e vegetais, aumento dos níveis de endogamia nas populações, modificações nas interações bióticas (polinização, dispersão de sementes, predação, herbivoria e competição) e abióticas (temperatura do ar, intensidade luminosa e composição do solo).

É preciso entender a dinâmica das populações nos fragmentos e sua interação com os elementos da paisagem para que as práticas de manejo e conservação sejam eficientes. Por enquanto, sabe-se pouco sobre o impacto causado pela fragmentação sobre a genética e o sistema reprodutivo das espécies arbóreas. Alguns trabalhos tem mostrado que a fragmentação de habitats, provoca uma redução no tamanho da população e aumento do distúrbio ambiental podendo afetar o sistema de cruzamento (Coates \& Hamley, 1999 e Routley et al., 1999). 


\subsection{Efeito da fragmentação na genética de população de planta}

A fragmentação de habitat pode causar a perda da variação genética populacional de duas maneiras. Primeiramente, a brusca redução do tamanho populacional (bottlenecks), pode resultar em uma perda de alelos de baixa freqüência, devido aos indivíduos remanescentes conter apenas uma pequena amostra do "pool" gênico original (Frankel \& Soulé, 1981). A extensão no qual isto ocorrerá depende da extensão da perda de floresta e da estrutura genética das populações naturais presente no momento da fragmentação, a imediata perda na heterozigosidade será evidente apenas se o tamanho populacional apresentar uma grande redução (White et al., 1999). Após a perda alélica inicial, as populações remanescentes, que permanecem isoladas e com reduzido fluxo gênico por várias gerações, continuam a perder alelos devido a deriva genética e à endogamia, reduzindo a diversidade genética nos fragmentos (White et al., 1999). A deriva genética refere-se às mudanças aleatórias nas freqüências alélicas das populações através das gerações, levando a fixação e à perda de alelos e provocando uma redução da variação genética das populações (Falconer, 1996).

Outborg et al. (1991), mostram que um grande número de populações selvagens apresentaram uma associação positiva entre o tamanho efetivo da população e a variação genética, com o aumento da porcentagem de locos polimórficos, do número de alelos e heterozigosidade em populações maiores. Outros trabalhos têm mostrado que a fragmentação provoca a redução significativa da riqueza alélica, mas não detectam uma diminuição na heterozigosidade (Sun, 1996; White et al., 1999). Isso provavelmente deve-se ao fato de que alelos com freqüências moderadas contribuem mais na determinação da heterozigosidade que os alelos de baixas freqüências, sendo estes os mais propícios a serem perdidos em populações pequenas (White et al., 1999). Outros estudos revelaram que os efeitos da redução na variação genética em função da redução no tamanho populacional e isolamento 
populacional, em 3 espécies herbáceas e uma arbórea, devem-se mais ao efeito "bottlenecks" do que a deriva genética (Young et al., 1996). O efeito "bottlenecks" contribui para a perda de alelos, especialmente os raros (ou de baixa freqüência), e isto é muito mais efetivo que a perda de heterozigosidade (Barret \& Kohn, 1991).

A perda da diversidade genética tem implicações quanto a persistência de espécies e populações. Com baixos níveis de variação genética, elas tornam-se vulneráveis a extinção devido a fatores estocásticos e a redução da adaptação (fitness), que diminui a capacidade das espécies em responder adaptativamente as mudanças ambientais futuras (Falconer, 1996; Frankham, 1996).

Uma outra conseqüência da fragmentação em relação à genética é que as espécies têm sua sobrevivência comprometida devido a alterações nos padrões de troca de genes. Grant (1980) afirma que a entrada constante e alta de genes em uma população através do fluxo gênico é o fator mais importante na manutenção da coesão genética entre as populações de uma espécie. A redução do fluxo gênico devido ao aumento do grau de isolamento entre populações pequenas provoca a divergência genética entre elas (Harlt \& Clark, 1997). Muitas espécies possuem meios efetivos de dispersão de genes e com isso mantém altos níveis de variação genética dentro de populações com pouca diferenciação genética entre populações. Entretanto, a diversidade genética e estrutura podem ser alteradas se a fragmentação florestal modificar os padrões de dispersão de pólen e sementes (Foré et al., 1992). Em algumas espécies arbóreas foi observado que a fragmentação não levou ao aumento da divergência entre as populações, nem à redução na variação genética dentro de populações e nem nos níveis de fluxo gênico entre os fragmentos (Young et al., 1993; González-Astorga \& Núñes-Farfán, 2001).

$O$ isolamento age negativamente na riqueza ao diminuir a taxa ou o potencial de imigração ou de colonização, e depende das distâncias e das 
áreas de todos os fragmentos vizinhos, do arranjo espacial dos fragmentos de habitat, assim como das características do ambiente entre os fragmentos.

As espécies vegetais sensíveis aos efeitos da fragmentação ocorrem numa densidade populacional mais baixa em fragmentos menores e isto provavelmente reduz sua taxa de cruzamento e/ou sua fertilidade, levando a perda de diversidade genética nestes fragmentos menores. Espécies de fecundação cruzada e dependentes da polinização por animais mostram-se mais sensíveis à fragmentação, devido à possível diminuição dos polinizadores (Milligan et al., 1994). A atuação de pássaros e mamíferos na fragmentação é, geralmente, mais reduzida do que de morcegos e o vento (Saunders et al., 1991). Alguns trabalhos têm mostrado que a fragmentação, provocando a redução no tamanho da população e o aumento do distúrbio ambiental, pode afetar o sistema de cruzamento (Coates \& Hamley, 1999; Routley et al., 1999).

Segundo Saunders et al.(1991), populações pequenas de espécies arbóreas podem persistir por longos períodos de tempo, devido a longevidade de seu indivíduos. Plantas adultas de espécies arbóreas mostram-se menos sensíveis às mudanças de condições ambientais do que as juvenis (Ribeiro, 2002). Aldrich et al. (1998) dizem que devido à longevidade das espécies arbóreas, torna-se difícil a realização de estudos sobre os efeitos da fragmentação na estrutura genética das mesmas. Como muitos indivíduos adultos nos fragmentos já estavam nestas áreas quando elas ainda eram contínuas, estudos feitos a partir destes indivíduos irão revelar mais sobre a estrutura genética pré-existente, do que sobre os efeitos da fragmentação.

Em programas de conservação e manejo de populações é importante conhecer as variações de diversidade genética, do fluxo gênico e das taxas de fecundação cruzada em populações causadas por fatores ecológicos e antrópicos (Muona, 1990). 


\subsection{Myrciaria floribunda (West ex Willdenow) Berg (cambuí)}

Segundo Sobral (1993), Myrciaria floribunda (West ex Willdenow) Berg (cambuí) possui porte arbustivo a arbóreo. É uma espécie de grande diversidade de ambientes. No sul da América do Sul floresce de dezembro a junho e frutifica de julho a outubro.

$\mathrm{Na}$ região onde os fragmentos foram estudados, esta espécie foi no passado muito utilizada para mata-burro e rabo de tiradeira (usado em cangas de boi) (A. Silva, comunicação pessoal). 


\section{MATERIAL E MÉTODOS}

\subsection{Local de estudo}

Os fragmentos estudados encontram-se na APA Fernão Dias, ao redor do município de Camanducaia, MG, que apresentam as seguintes coordenadas: $22^{\circ} 45^{\prime} 30^{\prime \prime}$ de latitude sul e 56 09' de longitude oeste de

Greenwich. É uma região montanhosa, com aproximadamente $2000 \mathrm{~m}$ de altitude, e temperaturas predominantemente baixas, com chuvas concentradas entre os meses de outubro a fevereiro. Possui belas paisagens e clima agradável que proporciona grande potencial para o ecoturismo, ainda pouco explorado.

Segundo informações do subprojeto de levantamento florístico, dados meteorológicos específicos não existem para a região de Camanducaia. Dessa forma, os dados climáticos de Maria da Fé, MG, foram utilizados por estar mais próxima da área de estudo. Estes dados indicaram um clima Temperado Chuvoso Cwbl, segundo a classificação de Köepen (Ayoade, 1998), com verão fresco que se verifica até nas serras elevadas da zona tropical.

Os resultados obtidos das análises de solo do fragmento controle, feito pelo subprojeto de inventário da flora fanerogâmica, demonstraram, em relação a sua granulometria, uma alta porcentagem de areia, média de argila e baixa de silte, caracterizando-o como franco arenoso. A análise química indicou um solo fortemente ácido $(\mathrm{pH}=4,4)$. Foram verificadas altas taxas de $\mathrm{Al}(3,64), \mathrm{C}(8,08)$ 
e N $(0,63)$, e também elevada quantidade de matéria orgânica $(13,92 \mathrm{dag} / \mathrm{Kg})$, este solo é do tipo Latossolo Vermelho Amarelo (França, 2002).

A região possui uma vegetação exuberante, ainda que o uso do solo seja intenso pela agricultura e pecuária de leite. $O$ fragmento controle, conhecido na região como matão, apresenta uma cobertura vegetal constituída pela Floresta Ombrófila Mista Alti-Montana.

\subsubsection{Histórico de fragmentação}

A ocupação do sul de Minas tem suas origens do século XVI, simultaneamente à do interior do Rio de Janeiro e de São Paulo, na "esteira" das "entradas e bandeiras". Como conseqüência desses movimentos, iniciou-se um processo de formação de pequenos núcleos, onde era possível encontrar abrigo e alimentação durante as viagens dos bandeirantes (IBITU, 1998).

A região de Camanducaia é remanescente de um desses núcleos e seu povoamento deu-se em meados do século XVIII, sendo formada por aventureiros que andavam em busca de ouro e pedras preciosas. Sabe-se que as primeiras casas foram construídas pelos bandeirantes paulistas da região de Atibaia, que se fixaram às margens do Rio Camanducaia (SEBRAE, 1997).

Segundo moradores da região do entorno dos fragmentos que estão sendo estudados, a ocupação desta área se deu há aproximadamente 90 anos atrás, quando então começou a utilização dos recursos florestais para sobrevivência, formando apenas pequenas regiões desmatadas e isoladas dentro de um contínuo florestal. Segundo Gayer (1924), no início do século XX, os cultivos de cereais (milho e feijão), fumo, cana-de-açúcar, chá e café eram praticados na região. Havia a criação de gado suíno, bovino e em pequena escala, ovinos e caprinos. Mas o que se considerava como as maiores riquezas eram "as quedas d'água, para a produção de eletricidade, as madeiras de lei (quantidade apreciável) e pinho (em enorme quantidade), que começavam a serem exploradas". 
Ao longo do tempo, com o aumento da população e da utilização dos recursos da floresta, estas pequenas áreas desmatadas, antes isoladas se uniram, formando assim os fragmentos florestais por volta de 1950 (A. Buta, comunicação pessoal). Segundo o relatório do Diagnóstico Rápido Participativo (DRP) feito pela Organização Não Governamental Aguari (2001), o processo de desmatamento foi mais intenso 50 anos atrás, a partir da extração de araucária e o início da monocultura de Pinus pela Companhia Melhoramentos.

Em 1985, houve a estabilização destes fragmentos, alguns hoje se encontram em bom estado de conservação, apesar da entrada de gado dentro destes fragmentos, da exploração seletiva de algumas espécies madeireiras e da passagem de fogo ocasionalmente.

Os moradores desta região dizem perceber que as matas vem aumentando, nos últimos dez anos. Talvez porque não tem sido derrubada e está sendo usada pelo gado, principalmente durante o inverno, quando o pasto sofre o efeito das geadas. Esta tem sido uma prática usual e tradicional utilizada como técnica de manejo de gado e de conservação das matas pelas comunidades pesquisadas, o uso dos fragmentos florestais como área de pasto.

Hoje ao redor da maioria dos fragmentos tem-se pasto, cultura agrícola tradicional e orgânica (Figura 1). 


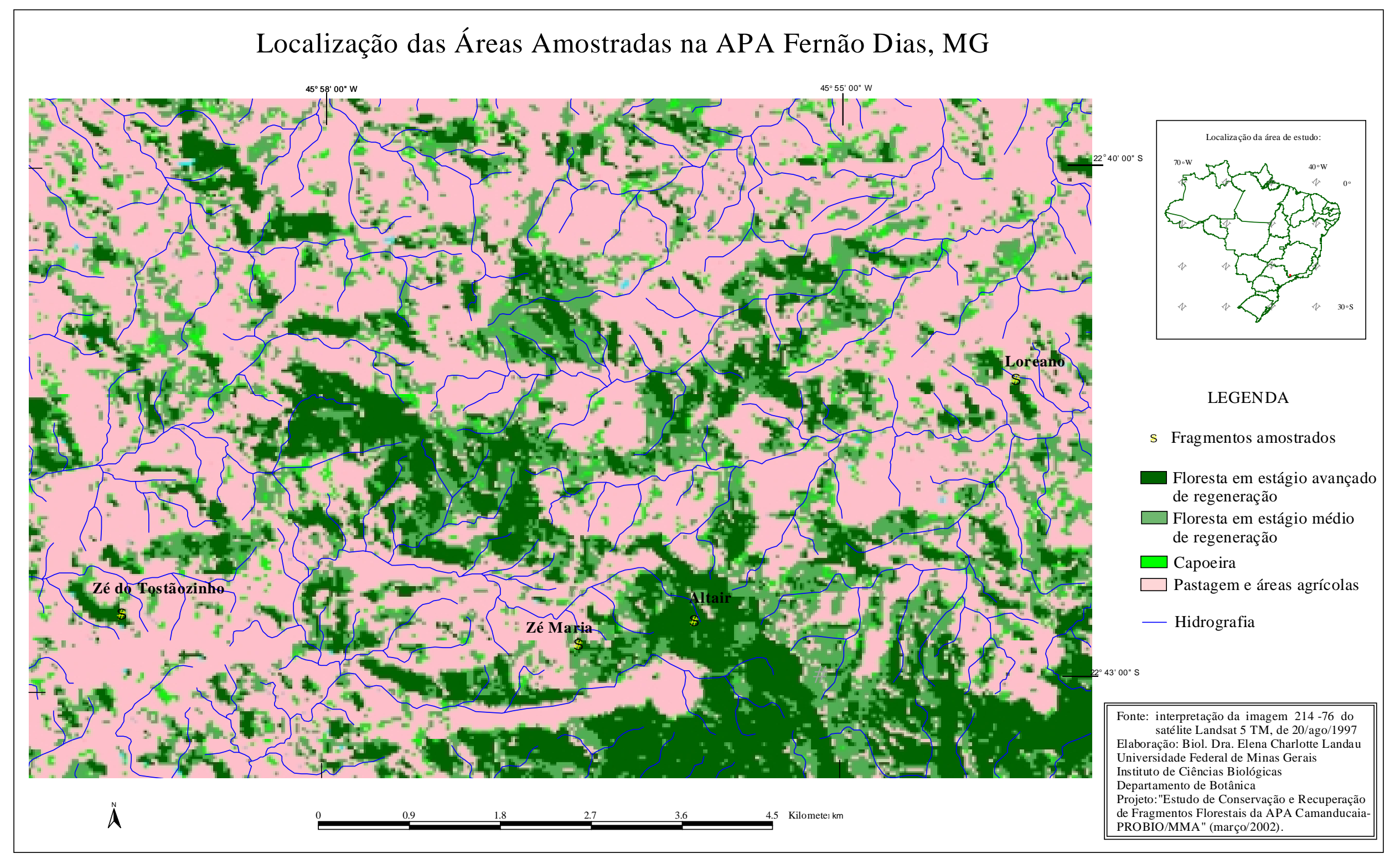

Figura 1 .Distribuição dos fragmentos estudados na paisagem 


\subsubsection{Descrição dos fragmentos}

A APA apresenta uma grande heterogeneidade ambiental, sua altitude média pode variar de $800 \mathrm{~m}$ (nas margens do Rio Jaguari em Extrema) até 2.100m (na Serra de São Domingos, Gonçalves), a diversidade de ecossistemas é também muito grande. $\mathrm{Na}$ área da APA, pode-se observar a ocorrência de diferentes ecossistemas em diferentes estágios de conservação ou regeneração, como as florestas semidecíduas, florestas ombrófilas, florestas de pinhais, florestas ripárias, florestas higrófilas (de brejo), e também grandes extensões de monoculturas de pinheiro, eucalipto e batata. Apesar do relevo acentuado, a bataticultura hoje é uma das atividades principais. E os agroecossistemas começam a surgir.

Há o predomínio de pequenas propriedades, com estradas que passam próximas aos fragmentos, o que facilita 0 acesso aos pesquisadores e aos proprietários que quando precisam utilizam os recursos destes.

O Sertão do Cantagalo, área onde se encontram o fragmento Loreano, com aproximadamente $1590 \mathrm{~m}$ de altitude (Tabela 1), é constituído, em sua maior parte, por agricultores, sendo que cerca de $70 \%$ destes dedica-se ao cultivo da batata tradicional. O restante cultiva milho, feijão, mandioquinha, em pequena produção para subsistência (Aguari, 2001). Este fragmento com uma área de aproximadamente 18 ha, apesar de ser bem menor que o fragmento controle, apresenta-se, visualmente, tão conservado quanto o fragmento controle e mais conservado que o fragmento Zé Tostãozinho. Ao seu redor temse pasto e um curso d'água, sendo considerado portanto uma mata ciliar. Este se encontra próximo a uma península do fragmento controle (ou matão).

O fragmento Zé Tostãozinho, não se encontra no sertão Cantagalo, possui uma área de aproximadamente 20 ha contando com a mata primária, plantio de pinheiros e capoeira, levando em consideração apenas a área de mata primária tem-se apenas 10 ha, sendo o menor fragmento estudado e se 
encontra mais distante do fragmento Loreano, Tabela 2. Além do plantio de pinheiro e capoeira há também pasto ao seu redor.

Dentro do fragmento controle, foram feitos duas réplicas (pontos Altair e Zé Maria), conforme tabela 1.

A população do Altair, localizada no fragmento controle, situa-se próximo à nascente do Rio Camanducaia e se encontra sob condições primitivas, sendo que não se tem notícias de grandes perturbações antrópicas no local, não se observam vestígios de exploração seletiva de madeira, os maiores danos observados referem-se à presença de gado na floresta, formando trilhas e afetando a vegetação de sub-bosque em alguns locais. A borda desta área está sujeita ao fogo produzido nas áreas de pastagens e culturas circundantes. Existem registros históricos de queimadas a mais de 60 anos atrás (França, 2002).

A população Zé Maria se encontra próxima a população do Altair, conforme tabela 2.

Tabela 1. Coordenadas e tamanho dos fragmentos de amostragem dos indivíduos de Myrciaria floribunda (cambuí).

\begin{tabular}{ccccc}
\hline Fragmentos & East & North & Altitude (m) & Área (ha) \\
\hline Matão (Altair) & 404020 & 7488139 & 1810 & 5810,27 \\
Matão (Zé Maria) & 402980 & 7487699 & 1868 & 5810,27 \\
Loreano & 407526 & 7490771 & 1590 & 18 \\
Zé Tostãozinho & 398666 & 7488274 & 1610 & 10 \\
\hline
\end{tabular}

Fonte: Menon (2001) e Aguari (2001)

Tabela 2. Distância (em quilômetros) entre os fragmentos estudados

\begin{tabular}{cccc}
\hline Fragmentos & Zé Maria & Altair & Zé Tostãozinho \\
\hline Loreano & 5,7 & 4,43 & 9,22 \\
Zé Maria & - & 1,26 & 4,1 \\
Altair & - & - & 5,27 \\
\hline
\end{tabular}

Fonte: Landau (2002) 


\subsection{Seleção da espécie}

Foi feito um levantamento rápido nos fragmentos, para saber quais espécies eles tinham em comum. Após este levantamento, detectou-se que a Cabralea canjerana, Psycotria sesselis, Aspidosperma sp (guatambú) e Myrciaria floribunda (cambuí) eram comuns e estavam presentes na maioria dos fragmentos. Coletou-se então folhas jovens destas quatro espécies para a confecção de géis. A espécie Myrciaria floribunda (cambuí), foi selecionada por apresentar melhor atividade enzimática e resolução no padrão de visualização das bandas nos géis.

\subsection{Coleta, transporte e armazenamento das folhas de cambuí}

Foram coletadas folhas jovens, de 40 indivíduos jovens, ao longo de trilhas já existentes, de cada fragmento. Como foram analisados dois pontos dentro de um fragmento controle e dois fragmentos menores, ao todo teve-se 160 indivíduos, numerados, plaqueteados e analisados.

As folhas foram embaladas em papel alumínio, identificadas internamente e externamente, e guardadas em caixa de isopor com gelo até o fim da coleta dos 40 indivíduos da população no fragmento, e logo eram colocadas em tanques de nitrogênio líquido $\left(-196^{\circ} \mathrm{C}\right)$. No Laboratório de Biologia de Populações de Plantas, na Universidade Federal de Minas Gerais, em Belo Horizonte, foram transferidas para o ultra-freezer $\left(-80^{\circ} \mathrm{C}\right)$ e mantidas até a realização da extração. Segundo Alfenas (1998), folhas coletadas e armazenadas da melhor maneira possível mantêm íntegras suas enzimas.

Considerando a longevidade das espécies arbóreas, a recente fragmentação da região analisada, e ao fato do cambuí ser uma espécie de sub-bosque, foram coletadas folhas de indivíduos jovens não-reprodutivos e pré-reprodutivos, para se ter certeza que estes indivíduos já estavam sofrendo influência da fragmentação. 


\subsection{Análises eletroforéticas}

As análises eletroforéticas foram realizadas no Laboratório de Biologia de Populações de Plantas/ICB da Universidade Federal de Minas Gerais.

A metodologia utilizada foi a eletroforese de isoenzimas em gel horizontal de amido a $13 \%$ descrita por Alfenas (1998), conforme em anexo, seguindo pequenas alterações, de forma a adequar o método para a espécie em estudo.

\subsubsection{Extração}

A extração das isoenzimas foi feita através da trituração em cadinhos de porcelana, de aproximadamente $0,02 \mathrm{~g}$ de tecido foliar em nitrogênio líquido e aproximadamente $1 \mathrm{ml}$ de solução de extração modificada (conforme tabela 3) a partir da solução de extração número 1 de Alfenas et al. (1998).

Tabela 3. Tampão de extração (pH 8,5) utilizado para a extração de isoenzimas de Myrciaria floribunda (cambuí). Protocolo modificado a partir da solução de extração número 1 de Alfenas et al. (1998).

\begin{tabular}{cc}
\hline REAGENTE & QUANTIDADE \\
\hline Fosfato de sódio bibásico & $0,6 \mathrm{~g}$ \\
Sacarose & $7 \mathrm{~g}$ \\
PVP-40 & $2,56 \mathrm{~g}$ \\
L-ácido ascórbico & $0,1 \mathrm{~g}$ \\
DIECA & $0,1 \mathrm{~g}$ \\
Metabisulfito de sódio & $0,05 \mathrm{~g}$ \\
Borato de sódio (Boráx) & $0,05 \mathrm{~g}$ \\
B-mercaptoetanol & $0,2 \mathrm{ml}$ \\
Polietilenoglicol-6000 & $1 \mathrm{~g}$ \\
Água deionizada ou destilada & $100 \mathrm{ml}$ \\
\hline
\end{tabular}

Após a extração das enzimas, a solução obtida foi absorvida em pedaços de papel de filtro (wick), com dimensões de $5 \times 12 \mathrm{~mm}$, os quais foram guardados em placas de "wick", contendo 8 repetições, no ultrafreezer até o momento da corrida. Foram colocadas 20 amostras em cada gel, além de dois 
pedaços de papel de filtro contendo solução marcadora de azul de bromofenol a $1 \%$ nas extremidades, para a marcação da linha de frente durante a migração.

\subsubsection{Tampões de eletrodo/gel e sistemas enzimáticos}

Realizou-se testes preliminares de sistemas de tampão gel/eletrodo combinados com sistemas enzimáticos.

A partir destes testes foram escolhidos sistemas enzimáticos pela sua boa resolução.

Foram testados 22 sistemas isoenzimáticos, listados em anexo, e três sistemas tampão cuba/gel: Citrato morfolina e Litio borato, segundo protocolo Alfenas (1998), e Histidina, segundo protocolo O'Malley (1980).

A partir destes testes, foram escolhidos sete sistemas enzimáticos e dois sistemas tampão cuba/gel pela sua boa resolução e constância. Os sistemas de tampão gel/eletrodo utilizados para cada sistema enzimático podem ser observados na tabela 4 e seu protocolo em anexo.

Tabela 4. Sistemas de tampão gel/eletrodo e sistemas enzimáticos utilizados.

\begin{tabular}{ccc}
\hline Tampão gel/eletrodo & Sistemas enzimáticos & Estrutura quaternária \\
\hline Citrato morfolina & G6PDH & Dimérica \\
& IDH & Dimérica \\
& UGPP & Monomérica \\
\hline Litio borato & TPI & Monomérica \\
& AAT & Não conhecida \\
& LAP & Monomérica \\
\hline
\end{tabular}

\subsubsection{Condições de corrida}

Os géis eram feitos no dia anterior e no dia seguinte as amostras eram aplicadas no géis. 
Durante a migração os géis foram mantidos à temperatura de aproximadamente $5^{\circ} \mathrm{C}$ (em refrigerador). Após 1 hora de corrida os papéis de filtro eram retirados. A corrida em Citrato morfolina levava cerca de 5-6 horas, quando o marcador de bromofenol atingia $8 \mathrm{~cm}$ de migração. Este sistema iniciava a corrida com $50 \mathrm{~mA}$. Para o sistema Lítio borato a corrida durava cerca de 9 a 10 horas com corrente inicial de $70 \mathrm{~mA}$.

Ao final da corrida os géis eram cortados em 5 fatias e preparados para a coloração específica e revelação de cada enzima.

As etapas subsequentes são o aquecimento em estufa à $35^{\circ} \mathrm{C}$, limpeza, interpretação e esquematização dos zimogramas, fixação e secagem dos géis para transparentização (Alfenas, 1998).

\subsubsection{Leitura e interpretação dos zimogramas}

As leituras dos zimogramas obtidos eram feitas logo após a revelação das isoenzimas.

As regiões de atividade foram numeradas em ordem decrescente de mobilidade, em relação à origem, de modo que a região com as bandas eletroforéticas de maior mobilidade para o sistema enzimático foi identificada como região 1 (ex: AAT-1). Para cada loco, o alelo de maior migração recebeu a denominação de $\mathrm{A}$ e os demais $\mathrm{B}, \mathrm{C}$, conforme a distância de migração seguinte.

\subsection{Metodologia estatística}

\subsubsection{Variabilidade genética}

A variabilidade genética foi caracterizada pelo uso dos seguintes índices de diversidade:

i) número médio de alelos por loco $(\hat{A})$; 
ii) número médio de alelos por loco polimórfico $\left(\hat{A}_{p}\right)$;

iii) porcentagem de locos polimórficos $(\hat{P})$;

iv) heterozigosidade média esperada $\left(\hat{H}_{e}\right)$;

v) heterozigosidade observada $\left(\hat{H}_{o}\right)$;

vi) freqüências alélicas, utilizando-se alelos de baixa freqüência.

O uso de freqüências alélicas são muito informativas nos estudos sobre a distribuição da diversidade dentro da paisagem, ou entre fragmentos florestais, e portanto auxiliando na interpretação dos dados sobre a estrutura genética.

As freqüências alélicas foram estimadas a partir da interpretação dos zimogramas, possibilitando a definição dos genótipos de cada indivíduo. Esta estimativa foi realizada contando-se o número de vezes que um alelo é encontrado em cada população e dividindo esse número pelo número total de alelos da população, segundo a fórmula abaixo:

$$
\hat{p}_{i j}=n_{i j} / n_{. j}
$$

onde:

$\hat{p}_{i j}=$ estimativa da freqüência do alelo $i$ na população $j$;

$n_{i j}=$ número de ocorrências do alelo i na amostra da população $j$;

$n_{j}=$ número total de alelos encontrados na amostra da população $j$.

A porcentagem de locos polimórficos $(\hat{P})$ foi calculada dividindo 0 número de locos polimórficos pelo número total de locos amostrados. Considerou-se loco polimórfico aqueles que possuíam alelos com uma freqüência de até $99 \%$.

O número médio de alelos por loco $(\hat{A})$ foi obtido somando-se todos os alelos observados e dividindo esse número pelo número total de locos amostrados.

A heterozigosidade esperada $\left(\hat{H}_{e}\right)$ foi estimada para cada loco, segundo Nei (1978): 


$$
\hat{H}_{e}=1-\Sigma p_{i}^{2}
$$

onde:

$p_{i}=$ freqüência do alelo $i$.

A estimativa da heterozigosidade média observada $\left(\hat{H}_{o}\right)$, calculada para cada loco individualmente, foi obtida diretamente da amostra a partir das freqüências genotípicas observadas, enquanto a heterozigosidade média observada foi obtida através da média aritmética de todos os locos analisados:

$$
\hat{H}_{o}=1-\Sigma p_{i i}
$$

onde:

$p_{i j}$ = freqüência observada de homozigotos, para o iésimo alelo no loco analisado.

Estas estimativas foram obtidas utilizando-se o programa BIOSYS-2 (versão original de Swofford e Selander, 1981; atualizado por Black W. C.,1997).

A partir das freqüências alélicas, foram estimadas as freqüências genotípicas esperadas para os homozigotos e heterozigotos.

A verificação dos desvios da panmixia foi feita através de teste do Quiquadrado e estatística $f$, executado pelo programa BIOSYS-2 (versão original de Swofford e Selander, 1981; atualizado por Black W. C., 1997).

A adequação ao modelo de Equilíbrio de Hardy-Weinberg (EHW) foi verificada através do coeficiente de endogamia ou índice de fixação ( $f$ de Wright) dentro de cada população (Weir, 1990). O índice de fixação indica a fração de redução na heterozigosidade em relação aos valores esperados em uma população de acasalamento aleatório em EHW: 


$$
f=\frac{\left(H_{e}-H_{o}\right)}{H_{e}}
$$

Uma população está em EHW caso $f=0$, para valores menores que zero, há um excesso de heterozigotos, já valores superiores à zero, indicam um excesso de homozigotos (Weir, 1990).

Segundo Brown e Weir (1983), um dos fatores que podem levar à não adequação das freqüências genotípicas ao EHW é o sistema de cruzamento, isto pode ser testado através do modelo de Equilíbrio de Endogamia de Wright (EEW), que considera o modelo de cruzamento misto, ou seja, acasalamentos aleatórios e auto-fecundação. Este modelo leva em consideração ainda o índice de fixação ( $f$ de Wright) para os cálculos das freqüências genotípicas esperadas.

\subsubsection{Estrutura genética}

A estrutura genética populacional foi determinada através da estatística $f$ de Wright (Wright, 1965, 1978), pelo método de Weir \& Cockerham (1984).

As estatísticas $f$ são constituídas de 3 índices:

i) $f$, coeficiente de endogamia dentro de populações devido aos acasalamentos não casuais,

ii) $\theta_{p}$, coeficiente de endogamia devido à subdivisão de populações, que representa a diferenciação genética entre populações,

iii) $F$, incorpora os efeito de acasalamentos não casuais dentro de populações e o efeito de subdivisão de populações.

Estas estimativas foram obtidas utilizando-se o programa TFPGA (Miller, 1997). 


\subsubsection{Fluxo gênico}

O fluxo gênico foi determinado pelo procedimento de Barton \& Slatkin (1986), através de freqüências alélicas obtidas de isoenzimas. $O \log$ de $N_{m}$, 0 número médio de migrantes entre populações locais por geração (onde $N=$ tamanho da população e $m=$ taxa de fluxo gênico) é linearmente relacionado ao log da freqüência média de alelos privados, ou seja dos alelos com baixa frequência ou raros. Os valores de $N_{m}$ também foram estimados através da seguinte fórmula:

$$
N_{m}=\left(1-F_{S T}\right) / 4 \times F_{S T}
$$

onde:

$F_{S T}=$ diversidade genética entre populações.

Segundo Hamrick \& Nason (2000), de modo geral as estimativas de fluxo gênico baseadas em Fst são empiricamente mais aceitáveis, pois são baseados em todos os dados de frequência gênica, e portanto menos sensíveis aos erros que as estimativas baseadas em alelos raros.

\subsubsection{Tamanho efetivo populacional}

O conhecimento do tamanho efetivo populacional $\left(N_{e}\right)$ é fundamental para a conservação a longo termo de uma espécie, sendo o fator central para a determinação de uma população mínima viável (PMV). Apesar de ter definições vagas, uma série de incertezas e arbitrariedades, esse é um meio de avaliar e trabalhar a questão da conservação de populações e, por conseqüência, de espécies (Moraes et al., 1999).

O tamanho efetivo de cada população $\left(N_{e}\right)$ foi estimado, segundo metodologia proposta por (Vencovsky, 1997): 


$$
\hat{N}_{e}=n /(1+f)
$$

onde:

$n=$ número total de indivíduos amostrados na população e $f=$ coeficiente de endogamia na população. 


\section{RESULTADOS}

São apresentados a seguir os resultados das análises dos sistemas enzimáticos obtidos neste estudo, bem como as análises estatísticas descritas na metodologia.

\subsection{Interpretação genética dos sistemas enzimáticos}

Considerando a estrutura quaternária das enzimas, segundo Wendal \& Weeden (1989), a herança codominante e os padrões de bandas dos heterozigotos foram analisados seis sistemas enzimáticos (Tabela 5):

\section{Glucose 6-Fosfato desidrogenase (G6PDH)}

Este sistema apresentou duas zonas de atividades, sendo a mais catódica interpretada como um loco polimórfico, dialélico e a enzima formada por duas subunidades (dímero). A outra região apresentou resolução ruim e de difícil interpretação genética, por isso não foi incluída na análise dos dados.

\section{Isocitrato desidrogenase (IDH)}

Neste sistema foi observada uma zona de atividade, um loco representado por uma enzima dimérica com dois alelos.

\section{Uridina difosfoglucose pirofosforilase (UGPP)}

Neste sistema foi observada uma zona de atividade, um loco representado por uma enzima dimérica com dois alelos. 


\section{Leucina aminopeptidase (LAP)}

Este sistema apresentou uma zona de atividade, com um loco polimórfico, representado por uma enzima monomérica com três alelos.

\section{Triose-fosfato isomerase (TPI)}

Este sistema apresentou uma zona de atividade, com um loco monomórfico (um alelo), representado por uma enzima monomérica.

\section{Amino aspartato transferase (AAT)}

Este sistema apresentou três zonas de atividades, sendo a de maior mobilidade com resolução ruim e de difícil interpretação genética, por isso não foi incluída na análise dos dados. Os outros dois locos foram interpretados como uma enzima monomérica. Os dois locos foram polimórficos, tendo o loco dois, três alelos e o loco três, dois alelos.

Tabela 5. Sistemas enzimáticos utilizados, locos e alelos analisados neste trabalho.

\begin{tabular}{cccc}
\hline $\begin{array}{c}\text { Sistemas } \\
\text { enzimáticos }\end{array}$ & $\begin{array}{c}\text { Número de locos } \\
\text { encontrados }\end{array}$ & $\begin{array}{c}\text { Número de locos } \\
\text { analisados }\end{array}$ & $\begin{array}{c}\text { Número de alelos } \\
\text { analisados }\end{array}$ \\
\hline G6PDH & 2 & 1 & 2 \\
IDH & 1 & 1 & 2 \\
UGPP & 1 & 1 & 2 \\
LAP & 1 & 1 & 3 \\
TPI & 1 & 1 & 1 \\
AAT & 3 & 2 & $3 / 2$ \\
\hline Total & $\mathbf{9}$ & $\mathbf{7}$ & $\mathbf{1 5}$ \\
\hline
\end{tabular}

Nos ítens 2, 3, e 4 são apresentados respectivamente os dados referentes à diversidade e estrutura genética das quatro populações de cambuí. 


\subsection{Diversidade genética}

As estimativas dos parâmetros de diversidade genética foram obtidas utilizando as freqüências dos alelos encontrados em cada população (Tabela 6). A porcentagem de locos polimórficos foi igual para as quatro populações. $O$ número médio de alelos por loco polimórfico foi igual para os dois fragmentos menores $(2,0)$ e menor que o valor encontrado para as duas populações do fragmento controle $(2,14)$.

A heterozigosidade média observada apresentou um decréscimo nos fragmentos menores, reduzindo de 0,386 e 0,347 nas populações do fragmento controle (Altair e Zé Maria, respectivamente), para 0,332 e 0,288 nas populações Zé Tostãozinho e Loreano, respectivamente.

Tabela 6. Estimativas de diversidade genética, para quatro populações de cambuí, a partir de seis sistemas enzimáticos, totalizando sete locos e 15 alelos. Os números entre parênteses referem-se aos desvios padrões.

\begin{tabular}{ccccc}
\hline Índices de diversidade & Zé Tostãozinho & Loreano & Zé Maria & Altair \\
\hline$\hat{H}_{e}$ (todos os locos) & 0,324 & 0,350 & 0,404 & 0,385 \\
$\hat{H}_{e}$ (locos polimórficos) & $(0.075)$ & $(0,072)$ & $(0,071)$ & $(0,076)$ \\
& 0,328 & 0,355 & 0,409 & 0,391 \\
$\hat{H}_{o}$ (todos os locos) & $(0,076)$ & $(0,073)$ & $(0,072)$ & $(0,077)$ \\
$\hat{A}$ & 0,332 & 0,288 & 0,347 & 0,386 \\
& $(0,077)$ & $(0,074)$ & $(0,061)$ & $(0,075)$ \\
$\hat{A}_{p}$ & 2,00 & 2,00 & 2,14 & 2,14 \\
& $(0,22)$ & $(0,22)$ & $(0,26)$ & $(0,26)$ \\
$\hat{P}$ (critério 0,95 e 0,99) & 2,33 & 2,33 & 2,5 & 2,5 \\
& 85,71 & 85,71 & 85,71 & 85,71 \\
\hline
\end{tabular}

\subsection{Estrutura genética}

As freqüências alélicas dos seis sistemas enzimáticos, das quatro populações de cambuí são apresentadas na Tabela 7. 
Tabela 7. Freqüências alélicas de sete locos isoenzimáticos em quatro populações de Myrciaria floribunda (cambuí).

\begin{tabular}{|c|c|c|c|c|}
\hline \multirow[b]{2}{*}{ Loco } & \multicolumn{4}{|c|}{ População } \\
\hline & Loreano & Zé Tostãozinho & Matão (Zé Maria) & Matão (Altair) \\
\hline \multicolumn{5}{|l|}{$\overline{U G P P-1}$} \\
\hline$(\mathrm{N})$ & 36 & 37 & 39 & 39 \\
\hline $\begin{array}{l}\text { A } \\
B\end{array}$ & $\begin{array}{l}0.903 \\
\mathbf{0 . 0 9 7}\end{array}$ & $\begin{array}{l}0.838 \\
\mathbf{0 . 1 6 2}\end{array}$ & $\begin{array}{l}0.564 \\
\mathbf{0 . 4 3 6}\end{array}$ & $\begin{array}{l}0.731 \\
0.269\end{array}$ \\
\hline \multicolumn{5}{|l|}{ IDH-1 } \\
\hline$(\mathrm{N})$ & 34 & 37 & 37 & 38 \\
\hline A & 0.544 & 0.486 & 0.365 & 0.579 \\
\hline B & 0.456 & 0.514 & 0.635 & 0.421 \\
\hline \multicolumn{5}{|c|}{ G6PDH-1 } \\
\hline$(\mathrm{N})$ & 38 & 39 & 35 & 35 \\
\hline A & 0.697 & 0.474 & 0.257 & 0.371 \\
\hline B & 0.303 & 0.526 & 0.743 & 0.629 \\
\hline \multicolumn{5}{|l|}{ LAP-1 } \\
\hline$(\mathrm{N})$ & 38 & 38 & 38 & 39 \\
\hline A & 0.500 & 0.658 & 0.382 & 0.423 \\
\hline B & 0.500 & 0.342 & 0.513 & 0.436 \\
\hline C & 0.000 & 0.000 & 0.105 & 0.141 \\
\hline \multicolumn{5}{|l|}{ TPI-1 } \\
\hline$(\mathrm{N})$ & 39 & 40 & 40 & 39 \\
\hline A & 1.000 & 1.000 & 1.000 & 1.000 \\
\hline \multicolumn{5}{|l|}{ AAT-2 } \\
\hline$(\mathrm{N})$ & 32 & 40 & 39 & 32 \\
\hline$A^{\prime}$ & 0.125 & 0.025 & 0.128 & 0.063 \\
\hline B & 0.172 & 0.038 & 0.128 & 0.078 \\
\hline \multirow{2}{*}{\multicolumn{5}{|c|}{ AAT-3 }} \\
\hline & & & & \\
\hline$(\mathrm{N})$ & 39 & 40 & 40 & 37 \\
\hline A & 0.731 & 0.688 & 0.538 & 0.581 \\
\hline B & 0.269 & 0.313 & 0.463 & 0.419 \\
\hline
\end{tabular}

N= número de indivíduos analisados

Comparando as freqüências alélicas das quatro populações, no loco UGPP-1, nota-se uma maior freqüência do alelo $A$, e menor freqüência do alelo $B$ nos fragmentos menores (Loreano e Zé Tostãozinho). Isto ocorre também para o loco AAT-3. 
No loco IDH-1, as freqüências alélicas nas quatro populações demonstram que suas proporções são intermediárias.

No loco G6PDH-1, nota-se uma maior freqüência do alelo $B$, e menor freqüência do alelo $A$. Esta freqüência do alelo $B$ diminui nos fragmentos menores (Loreano e Zé Tostãozinho).

O loco LAP-1, apresenta uma maior freqüência para o alelo $A$ nas populações dos fragmentos menores, e uma ausência do alelo C nas populações dos fragmentos menores.

Para o loco AAT-2, os alelos A e B apresentaram baixa freqüência para as populações dos fragmentos Zé Tostãozinho e Altair.

Nas tabelas 8, 9, 10 e 11 observam-se a verificação das estimativas encontradas ao modelo do EHW para os fragmentos menores e o fragmento controle, respectivamente. 
Tabela 8. Verificação das estimativas encontradas ao modelo do EHW, através dos testes do $\mathrm{X}^{2}$ para a população do fragmento Loreano.

\begin{tabular}{lllllll}
\hline Loco & Genótipos & No & Ne & $\mathbf{X}^{2}$ & GL X $^{2}$ & $\mathbf{P X}^{2}$ \\
\hline
\end{tabular}

UGPP-1

$\begin{array}{lll}\text { A-A } & 29 & 29.296 \\ \text { A-B } & 7 & 6.408 \\ \text { B-B } & 0 & 0.296\end{array}$

$\mathrm{IDH}-1$

$\begin{array}{lll}\text { A-A } & 17 & 9.940 \\ \text { A-B } & 3 & 17.119 \\ \text { B-B } & 14 & 6.940\end{array}$

G6PDH-1

$\begin{array}{rll}\text { A-A } & 19 & 18.373 \\ \text { A-B } & 15 & 16.253 \\ \text { B-B } & 4 & 3.373\end{array}$

LAP-1

$\begin{array}{lll}\text { A-A } & 12 & 9.373 \\ \text { A-B } & 14 & 19.253 \\ \text { B-B } & 12 & 9.373\end{array}$

AAT-2

\begin{tabular}{|c|c|c|}
\hline$A-A$ & 0 & 0.444 \\
\hline$A-B$ & 0 & 1.397 \\
\hline$A-C$ & 8 & 5.714 \\
\hline B-B & 1 & 0.873 \\
\hline B-C & 9 & 7.857 \\
\hline C-C & 14 & 15.714 \\
\hline
\end{tabular}

AAT-3

$\begin{array}{lll}\text { A-A } & 20 & 20.727 \\ \text { A-B } & 17 & 15.545 \\ \text { B-B } & 2 & 2.727\end{array}$


Tabela 9. Verificação das estimativas encontradas ao modelo do EHW, através dos testes do $X^{2}$ para a população do fragmento Zé Tostãozinho.

\begin{tabular}{lcll}
\hline Loco & Genótipos & No & Ne \\
\hline UGPP-1 & & & \\
& A-A & 25 & 25.904 \\
& A-B & 12 & 10.192 \\
& B-B & 0 & 0.904
\end{tabular}

$\mathrm{IDH}-1$

$\begin{array}{lll}\text { A-A } & 8 & 8.630 \\ \text { A-B } & 20 & 18.740 \\ \text { B-B } & 9 & 9.630\end{array}$

G6PDH-1

$\begin{array}{lll}\text { A-A } & 11 & 8.649 \\ \text { A-B } & 15 & 19.701 \\ \text { B-B } & 13 & 10.649\end{array}$

$0.172 \quad 1 \quad 0.678^{\text {ns }}$

LAP-1

$\begin{array}{lll}\text { A-A } & 15 & 16.333 \\ \text { A-B } & 20 & 17.333 \\ \text { B-B } & 3 & 4.333\end{array}$

AAT-2

$\begin{array}{lll}\text { A-A } & 0 & 0.013 \\ \text { A-B } & 0 & 0.076 \\ \text { A-C } & 2 & 1.899 \\ \text { B-B } & 0 & 0.038 \\ \text { B-C } & 3 & 2.848 \\ \text { C-C } & 35 & 35.127\end{array}$

AAT-3

$\begin{array}{lll}\text { A-A } & 19 & 18.797 \\ \text { A-B } & 17 & 17.405 \\ \text { B-B } & 4 & 3.797\end{array}$

0.141

3

$0.987^{\text {ns }}$

$\mathrm{No}=$ freqüência observada; $\mathrm{Ne}=$ freqüência esperada; ${ }^{*} \mathrm{P}<0.05,{ }^{*} \mathrm{P}<0.01$ e ns= não significativo. 
Tabela 10. Verificação das estimativas encontradas ao modelo do EHW, através dos testes do $X^{2}$ para a população do fragmento controle (Zé Maria).

\begin{tabular}{llll}
\hline Loco & Genótipos & No & Ne \\
\hline UGPP-1 & & & \\
& A-A & 13 & 12.286 \\
& A-B & 18 & 19.429 \\
& B-B & 8 & 7.286
\end{tabular}

$\mathrm{IDH}-1$

$\begin{array}{lll}\text { A-A } & 6 & 4.808 \\ \text { A-B } & 15 & 17.384 \\ \text { B-B } & 16 & 14.808\end{array}$

G6PDH-1

$\begin{array}{lll}\text { A-A } & 1 & 2.217 \\ \text { A-B } & 16 & 13.565 \\ \text { B-B } & 18 & 19.217\end{array}$

LAP-1

$\begin{array}{lll}\text { A-A } & 8 & 5.413 \\ \text { A-B } & 10 & 15.080 \\ \text { A-C } & 3 & 3.093 \\ \text { B-B } & 13 & 9.880 \\ \text { B-C } & 3 & 4.160 \\ \text { C-C } & 1 & 0.373\end{array}$

AAT-2

$\begin{array}{lll}\text { A-A } & 0 & 0.584 \\ \text { A-B } & 8 & 1.299 \\ \text { A-C } & 2 & 7.532 \\ \text { B-B } & 0 & 0.584 \\ \text { B-C } & 2 & 7.532 \\ \text { C-C } & 27 & 21.468\end{array}$

AAT-3

\begin{tabular}{llllll} 
A-A & 14 & 11.430 & & & \\
A-B & 15 & 20.139 & & & \\
B-B & 11 & 8.430 & & & \\
& & & 2.672 & 1 & $0.102^{\text {ns }}$ \\
\hline
\end{tabular}

$\mathrm{No}=$ freqüência observada; $\mathrm{Ne}=$ freqüência esperada; ${ }^{*} \mathrm{P}<0.05,{ }^{*} \mathrm{P}<0.01$ e ns= não significativo. 
Tabela 11. Verificação das estimativas encontradas ao modelo do EHW, através dos testes do $X^{2}$ para a população do fragmento controle (Altair).

\begin{tabular}{llll}
\hline Loco & Genótipos & No & Ne \\
\hline UGPP-1 & & & \\
& A-A & 19 & 20.727 \\
& A-B & 19 & 15.545 \\
& B-B & 1 & 2.727
\end{tabular}

$\mathrm{IDH}-1$

$\begin{array}{lll}\text { A-A } & 13 & 12.613 \\ \text { A-B } & 18 & 18.773 \\ \text { B-B } & 7 & 6.613\end{array}$

G6PDH-1

$\begin{array}{lll}\text { A-A } & 5 & 4.710 \\ \text { A-B } & 16 & 16.580 \\ \text { B-B } & 14 & 13.710\end{array}$

$2.006 \quad 1 \quad 0.157^{\text {ns }}$

LAP-1

$\begin{array}{lll}\text { A-A } & 12 & 6.857 \\ \text { A-B } & 8 & 14.571 \\ \text { A-C } & 1 & 4.714 \\ \text { B-B } & 10 & 7.286 \\ \text { B-C } & 6 & 4.857 \\ \text { C-C } & 2 & 0.714\end{array}$

AAT-2

$\begin{array}{lll}\text { A-A } & 0 & 0.095 \\ \text { A-B } & 0 & 0.317 \\ \text { A-C } & 4 & 3.492 \\ \text { B-B } & 0 & 0.159 \\ \text { B-C } & 5 & 4.365 \\ \text { C-C } & 23 & 23.571\end{array}$

AAT-3

$13.34230 .004^{\star *}$

$0.066 \quad 1 \quad 0.797^{\text {ns }}$

$0.044 \quad 1 \quad 0.833^{\text {ns }}$


Analisando os resultados destas tabelas, observou-se que para 0 fragmento Loreano, a hipótese nula de adequação ao modelo do EHW foi rejeitada apenas para o loco IDH-1. Para o fragmento Zé Tostãozinho as diferenças nas freqüências alélicas de todos os locos não foram significativas. Para a população Zé Maria, a hipótese nula de adequação ao modelo do EHW foi rejeitada apenas para o loco AAT-2. Para a população do Altair a hipótese nula de adequação ao modelo do EHW foi rejeitada apenas para o loco LAP-1.

Outro fator a ser considerado em relação aos efeitos da fragmentação é a endogamia. Nas Tabelas 12, 13, 14 e 15, a seguir, podem ser observadas as estimativas obtidas para o índice de fixação de Wright $(\hat{f})$ dos locos analisados. Valores positivos de $\hat{f}$ indicam aumento na freqüência de homozigotos das populações e valores negativos, diminuição da freqüência de homozigotos.

Tabela 12. Número de heterozigotos observados e esperados $\left(\hat{H}_{o}\right.$ e $\left.\hat{H}_{e}\right)$, índices de fixação de Wright $(\hat{f})$ e teste $\mathbf{X}^{2}$, para a população do fragmento Loreano.

\begin{tabular}{|c|c|c|c|c|c|c|}
\hline Loco & $\hat{H}_{o}$ & $\hat{H}_{e}$ & $\hat{f}$ & D & $x^{2}$ & $\mathbf{P}$ \\
\hline $\begin{array}{l}\text { UGPP-1 } \\
\text { IDH-1 }\end{array}$ & $\begin{array}{l}7 \\
3\end{array}$ & $\begin{array}{l}6.408 \\
17.119\end{array}$ & $\begin{array}{l}-0.108 \\
\mathbf{0 . 8 2 2}\end{array}$ & $\begin{array}{l}0.092 \\
-0.825\end{array}$ & $\begin{array}{l}0.32 \\
23.82\end{array}$ & $\begin{array}{l}0.5744^{n s} \\
0.0000^{\text {*** }}\end{array}$ \\
\hline G6PDH-1 & 15 & 16.253 & 0.065 & -0.077 & 0.23 & $0.6300^{\mathrm{ns}}$ \\
\hline LAP-1 & 14 & 19.253 & 0.263 & -0.273 & 2.91 & $0.0883^{n s}$ \\
\hline AAT-2 & 17 & 14.968 & -0.154 & 0.136 & 1.06 & $0.3026^{n s}$ \\
\hline AAT-3 & 17 & 15.545 & -0.108 & 0.094 & 0.35 & $0.5539^{n s}$ \\
\hline
\end{tabular}

${ }^{*} \mathrm{P}<0.05,{ }^{* *} \mathrm{P}<0.01,{ }^{* * *} \mathrm{P}<0.001$ e ns $=$ não significativo

Os desvios apresentados pelos locos mostraram que em IDH-1 há um excesso de homozigotos, enquanto em AAT-2, há um excesso de 
heterozigotos. O valor de $\hat{f}$ foi alto e significativo apenas para o loco IDH-1, para o fragmento Loreano, Tabela 12.

Tabela 13. Número de heterozigotos observados e esperados $\left(\hat{H}_{o}\right.$ e $\left.\hat{H}_{e}\right)$, índices de fixação de Wright $(\hat{f})$ e teste $\mathbf{X}^{2}$, para a população do fragmento Zé Tostãozinho.

\begin{tabular}{lllllll}
\hline Loco & $\hat{H}_{o}$ & $\hat{H}_{e}$ & $\hat{f}$ & $\mathbf{D}$ & $\mathbf{x}^{2}$ & $\mathbf{P}$ \\
\hline UGPP-1 & 12 & 10.192 & $\mathbf{- 0 . 1 9 4}$ & 0.177 & 1.20 & $0.2740^{\mathrm{ns}}$ \\
IDH-1 & 20 & 18.740 & -0.082 & 0.067 & 0.17 & $0.6784^{\mathrm{ns}}$ \\
G6PDH-1 & 15 & 19.701 & $\mathbf{0 . 2 2 9}$ & -0.239 & 2.28 & $0.1311^{\mathrm{ns}}$ \\
LAP-1 & 20 & 17.333 & -0.169 & 0.154 & 0.92 & $0.3365^{\text {ns }}$ \\
AAT-2 & 5 & 4.823 & -0.050 & 0.037 & 0.09 & $0.7665^{\text {ns }}$ \\
AAT-3 & 17 & 17.405 & 0.011 & -0.023 & 0.02 & $0.8815{ }^{\text {ns }}$ \\
\hline
\end{tabular}

${ }^{*} \mathrm{P}<0.05,{ }^{* *} \mathrm{P}<0.01$ e ns $=$ não significativo

$\mathrm{Na}$ Tabela 13 os desvios apresentados pelos locos mostraram que em G6PDH-1 há um excesso de homozigotos, enquanto em UGPP-1, há um excesso de heterozigotos. 
Tabela 14. Número de heterozigotos observados e esperados $\left(\hat{H}_{o}\right.$ e $\left.\hat{H}_{e}\right)$, índices de fixação de Wright $(\hat{f})$ e teste $\mathbf{x}^{2}$, para a população do fragmento controle (Zé Maria).

\begin{tabular}{lcclllll}
\hline Loco & $\hat{H}_{o}$ & $\hat{H}_{e}$ & $\hat{f}$ & $\mathbf{D}$ & $\mathbf{x}^{2}$ & \multicolumn{2}{l}{$\mathbf{P}$} \\
\hline UGPP-1 & 18 & 19.429 & 0.061 & -0.074 & 0.22 & $0.6418^{\mathrm{ns}}$ \\
IDH-1 & 15 & 17.384 & 0.125 & -0.137 & 0.71 & $0.3978^{\mathrm{ns}}$ \\
G6PDH-1 & 16 & 13.565 & $-\mathbf{0 . 1 9 7}$ & 0.179 & 1.16 & $0.2814^{\mathrm{ns}}$ \\
LAP-1 $_{\text {AAT-2 }}^{16}$ & 22.333 & $\mathbf{0 . 2 7 4}$ & -0.284 & 4.96 & $0.0259^{\star}$ \\
AAT-3 & 12 & 16.364 & 0.257 & -0.267 & 4.97 & $0.0258^{*}$ \\
& 15 & 20.139 & 0.246 & -0.255 & 2.67 & $0.1022^{\text {ns }}$ \\
\hline
\end{tabular}

${ }^{*} \mathrm{P}<0.05,{ }^{* *} \mathrm{P}<0.01$ e ns $=$ não significativo

$\mathrm{Na}$ Tabela 14 os desvios apresentados pelos locos mostraram que em LAP-1 há um excesso de homozigotos, enquanto em G6PDH-1, há um excesso de heterozigotos. O valor de $\hat{f}$ foi significativo para o loco LAP-1 e AAT-2. 
Tabela 15. Número de heterozigotos observados e esperados $\left(\hat{H}_{o}\right.$ e $\left.\hat{H}_{e}\right)$, índices de fixação de Wright $(\hat{f})$ e teste $\mathbf{X}^{2}$, para a população do fragmento controle (Altair).

\begin{tabular}{lllllll}
\hline Loco & $\hat{H}_{o}$ & $\hat{H}_{e}$ & $\hat{f}$ & $\mathbf{D}$ & $\mathbf{x}^{2}$ & $\mathbf{P}$ \\
\hline UGPP-1 & 19 & 15.545 & -0.238 & 0.222 & 1.98 & $0.1598^{\mathrm{ns}}$ \\
IDH-1 & 18 & 18.773 & 0.028 & -0.041 & 0.07 & $0.7969^{\mathrm{ns}}$ \\
G6PDH-1 & 16 & 16.580 & 0.021 & -0.035 & 0.04 & $0.8338^{\mathrm{ns}}$ \\
LAP-1 & 15 & 24.143 & $\mathbf{0 . 3 7 1}$ & -0.379 & 9.86 & $0.0017^{*}$ \\
AAT-2 & 9 & 8.175 & -0.118 & 0.101 & 0.56 & $0.4545^{\text {ns }}$ \\
AAT-3 & 23 & 18.260 & $-\mathbf{0 . 2 7 7}$ & 0.260 & 2.56 & $0.1095{ }^{\text {ns }}$ \\
\hline
\end{tabular}

${ }^{*} \mathrm{P}<0.05,{ }^{* *} \mathrm{P}<0.01$ e ns= não significativo

Os desvios apresentados pelos locos mostraram que em LAP-1 há um excesso de homozigotos, enquanto em AAT-3, há um excesso de heterozigotos. O valor de $\hat{f}$ foi significativo apenas para o loco LAP-1, conforme Tabela 15.

$\mathrm{Na}$ Tabela 16 foram estimados o coeficiente de endogamia total $(\hat{F})$, coeficiente de endogamia médio das subpopulações $(\hat{f})$ e o coeficiente de coancestralidade $\left(\hat{\boldsymbol{\theta}}_{p}\right)$ a partir das freqüências alélicas. A estimativa de $\hat{\boldsymbol{\theta}}_{p}$ neste trabalho é equivalente a estimativa $F_{S T}$ de Wright (1965). 
Tabela 16. Estimativas dos parâmetros $\hat{f}, \hat{\theta}_{p}$ e $\hat{F}$ de quatro populações de Myrciaria floribunda (cambuí).

\begin{tabular}{cccc}
\hline Loco & $\hat{f}$ & $\hat{\boldsymbol{\theta}}_{p}$ & $\hat{F}$ \\
\hline UGPP-1 & $-0,0924$ & 0,091 & 0,0060 \\
IDH-1 & 0,2248 & 0,0190 & 0,2395 \\
G6PDH-1 & 0,0629 & 0,1238 & 0,1789 \\
LAP-1 & 0,2197 & 0,0311 & 0,2440 \\
AAT-2 & 0,0231 & 0,0429 & 0,0651 \\
AAT-3 & $-0,0188$ & 0,0299 & 0,0116 \\
\hline Média dos locos & $\mathbf{0 , 0 8 6 4}$ & $\mathbf{0 , 0 5 5 5}$ & $\mathbf{0 , 1 3 7 1}$ \\
\hline
\end{tabular}

$\hat{f}=$ coeficiente de endogamia intrapopulacional; $\hat{\theta}_{p}=$ coeficiente de coancestralidade de populações; $\hat{F}=$ coeficiente de endogamia de todas as plantas nas quatro populações analisadas, ao nível de espécie.

Na Tabela 17 observa-se que a medida de diferenciação genética entre populações, avaliada pela distância genética de Nei, indica que o fragmento Loreano apresenta uma maior divergência genética com as duas populações dentro do fragmento controle, sendo esta divergência maior com a população Zé Maria. O fragmento Zé Tostãozinho também apresentou uma maior divergência genética com a população Zé Maria.

Tabela 17. Coeficientes de Nei (1978) de identidade (diagonal inferior) e de distância (diagonal superior) das populações de Myrciaria floribunda (cambuí).

\begin{tabular}{lcccc}
\hline População & $\mathbf{1}$ & $\mathbf{2}$ & $\mathbf{3}$ & $\mathbf{4}$ \\
\hline 1. Loriano & $* \star \star \star *$ & 0.020 & 0.085 & 0.036 \\
2. Zé do Tustãozinho & 0.980 & $* * * * *$ & 0.047 & 0.011 \\
3. Zé Maria & 0.919 & 0.954 & $* * * * *$ & 0.016 \\
4. Altair & 0.965 & 0.989 & 0.984 & $* * * * *$ \\
\hline
\end{tabular}




\section{DISCUSSÃo}

\subsection{Diversidade genética}

Os nove locos identificados (sete utilizados) em Myrciaria floribunda (cambuí) constituem-se os primeiros marcadores genéticos relatados para essa espécie, possibilitando que outros estudos genéticos possam ser realizados em populações desta espécie, como por exemplo, a determinação do sistema de cruzamento e estimativas de fluxo gênico direto.

De forma geral os valores encontrados para heterozigosidade foram elevados (entre 0,288 a 0,386), quando comparados com os resultados encontrados em outras espécies arbóreas tropicais alógamas já estudadas via isoenzimas.

Hamrick \& Godt (1990), em uma revisão de 653 estudos de diversidade genética por isoenzimas, encontraram uma diversidade genética média ao nível populacional de 0,149 para espécies arbóreas, 0,159 para espécies de ampla distribuição, 0,109 para espécies tropicais, 0,124 para espécies de polinização por animais. Mesmo a menor diversidade genética encontrada, no caso do fragmento Loreano $(0,288)$, foi superior às médias de todos estes casos.

Um outro exemplo de heterozigosidade elevada em populações naturais foi detectado em Bauhinia forficata, 0,451 (Santos, 1994). Este valor é maior que a heterozigosidade observada na população do Altair $(0,386)$, que foi a maior heterozigosidade encontrada das quatro populações.

Hamrick \& Murawski (1991), compararam as heterozigosidades médias de 16 espécies arbóreas raras com 16 espécies arbóreas comuns e observaram valores significativamente maiores para as comuns. As espécies 
raras apresentaram $42 \%$ de locos polimórficos e em média 2,14 alelos por loco polimórfico. As espécies mais comuns apresentaram $61 \%$ dos locos polimórficos e em média 3,17 alelos por loco polimórfico. Neste trabalho Myrciaria floribunda apresentou valor semelhante quanto número médio de alelos por loco polimórfico aos valores apresentados pelas espécies raras $(2,33)$, já quanto a porcentagem de locos polimórficos, este foi superior ao encontrado para as espécies comuns $(85,71)$.

As heterozigosidades observadas nas quatro populações foram bastante semelhantes. Nas populações Zé Tostãozinho e Altair as heterozigosidades observadas foram maiores que a esperada, indicando não ter havido problemas de amostragem. As populações dos fragmentos menores (Loreano e Zé Tostãozinho) apresentaram um declínio na riqueza alélica e na heterozigosidade observada em relação as populações utilizadas no fragmento controle.

A diminuição do número médio de alelos por loco nos fragmentos menores ocorreu provavelmente pela perda do alelo C para o sistema LAP-1 nos fragmentos Loreano e Zé Tostãozinho.

Esta perda alélica pode ter sido causada pelo efeito de deriva genética, ou pela própria amostragem utilizada para estes estudos de diversidade, ou pelo próprio efeito de amostragem de populações pequenas, devido a fragmentação, ou seja, a redução na riqueza alélica, deve-se possivelmente a diminuição acentuada do tamanho populacional, como efeito imediato da fragmentação.

A diminuição da riqueza alélica devida à fragmentação também foi observada na espécie arbórea Swietenia humilis por White et al. (1999), que analisaram somente indivíduos adultos em quatro populações:do uma população dentro de uma reserva, duas populações em dois fragmentos e uma população em uma área de pastagem. Estes autores encontraram que os alelos de baixa freqüência na população da reserva (controle) foram perdidos nos fragmentos. Ribeiro (2002), estudando o efeito da fragmentação na estrutura 
genética de Dalbergia nigra, em três fragmentos, também obteve resultado semelhante, encontrando uma diminuição na freqüência dos alelos, como também à perda de alguns desses alelos, em quatro dos cinco locos analisados.

De forma geral não foram encontradas diferenças entre populações em relação a heterozigosidade observada e esperada. Entretanto, nota-se uma tendência à redução nas heterozigosidades dos fragmentos menores em relação às duas populações dentro do fragmento controle.

Resumidamente os resultados quanto à diversidade alélica indicam que a redução detectada no número de alelos não refletiu no grau de heterozigosidade. Isto provavelmente decorre do fato que os alelos de baixa freqüência têm pouca influência na heterozigosidade e são os mais prováveis de serem perdidos imediatamente após a fragmentação (Taggart et al., 1990).

A situação observada no presente trabalho indica que mesmo apresentando elevadas heterozigosidades, uma perda de alelos pôde ser detectada, e como consequência uma redução na heterozigosidade nos fragmentos menores.

Uma explicação para os elevados valores de heterozigosidades encontrados e uma pequena diferenciação entre as heterozigosidades do fragmento controle e dos fragmentos menores pode estar relacionada à história de perturbação recente, com desmatamento ocorrido provavelmente há 50 anos (A. Silva, comunicação pessoal) e devido o efeito da deriva genética na diminuição da heterozigosidade ser cumulativo através das gerações (Hartl \& Clark, 1997).

No caso dos fragmentos e paisagem estudada, devido ao processo de história de perturbação e fagmentação recente, pode não ter ocorrido tempo suficiente após a fragmentação para uma mudança significativa na diversidade gênica, uma vez que o cambuí é uma espécie arbórea de crescimento lento e alta longevidade e provavelmente, estes indivíduos jovens estudados ainda são da primeira ou segunda geração após ter ocorrido a fragmentação. 
Alguns trabalhos com espécies arbóreas, também não encontraram redução na heterozigosidade em populações fragmentadas (Young et al., 1993; Coates \& Hamley, 1999; White et al., 1999; Colevatti et al., 2001).

Em relação ao índice de fixação dentro das quatro populações, de todos os locos analisados, apenas quatro locos não apresentaram aderência ao EHW, e destes quatro, apenas um loco, da população do Loreano, apresentou um alto nível positivo e muito significativo para o $f$ de Wright.

Como já enfatizado acima, devido a fragmentação na região ser recente e estes indivíduos analisados pertencerem a primeira ou segunda geração após a fragmentação, acredita-se que não houve tempo de detectar o efeito dessa fragmentação na endogamia desta espécie. Desta forma somente a partir de análises de progênies dos atuais eventos reprodutivos, esta afirmação poderia ser atribuída às conseqüências da fragmentação.

\subsection{Estrutura genética}

A maior parte da variabilidade encontra-se dentro das populações, havendo pouca divergência entre elas, o que pode ser verificado pela estimativa

obtida para $\hat{\theta}_{p}(0,0555)$, este resultado de distribuição da variabilidade genética entre e dentro das populações foi concordante com alguns trabalhos realizados com espécies arbóreas tropicais (Eguiarte et al., 1992; Harritt, 1991; Moraes, 1992).

Esperava-se encontrar uma maior divergência genética entre as populações dos fragmentos menores por estarem mais distantes $(9,22 \mathrm{Km})$, no entanto, a maior divergência genética encontrada foi entre a população Loreano e Zé Maria, cuja distância entre estas duas populações é de aproximadamente de 5,7 Km. Talvez estas diferenças, medidas em indivíduos jovens, reflita fluxos gênicos e o conseqüente estabelecimento de plantas, a partir de eventos reprodutivos prévios ao atual estágio de fragmentação. Desta forma somente a 
partir de análises de progênies dos atuais eventos reprodutivos, esta afirmação poderia ser atribuída às conseqüências da fragmentação.

A estimativa indireta do número de migrantes entre as populações dos indivíduos jovens foi $\mathrm{Nm}=4,25$. Este resultado foi semelhante ao encontrado por Hall et al. (1994), para Carapa guianensis $(\mathrm{Nm}=4,10)$ e maior que o resultado encontrado por Ribeiro (2002) ( $\mathrm{Nm}=2,9)$, a qual sugere que os indivíduos jovens de Dalbergia nigra estejam sofrendo uma redução no fluxo gênico como conseqüência da fragmentação. Segundo Hartl \& Clark (1997), valores de Nm superiores a 4,0 ndicam que as populações se comportam como uma única população panmítica, portanto estas quatro populações de cambuí pode ser considerada como uma única população panmítica.

As estimativas indiretas do fluxo gênico refletem taxas históricas de fluxo gênico na distribuição da variação genética atual ao invés de representarem os padrões de fluxo gênico atuante em uma única geração (Loveless, 1992). No caso deste trabalho, os indivíduos estudados podem ter vindo de diferentes ciclos de reprodução e de estabelecimento, ou seja a partir das variações supra-anuais de produção de sementes, com progênies segregando de forma distinta e plântulas sofrendo diferentes pressões de seleção.

\subsection{Biologia da espécie e conservação da diversidade genética}

Embora não tenham sido encontrados na literatura dados sobre os agentes polinizadores e dispersores, através de observações no campo verificou-se que a dispersão de sementes em cambuí deva ser realizada provavelmente por pássaros e a polinização por diferentes espécies de abelhas.

O fluxo gênico em populações fragmentadas de espécies arbóreas é influenciado pelas alterações ocasionadas nos agentes dispersores de sementes e pólens. Para espécies que possuem dispersão de sementes e polinização realizadas pela gravidade ou vento, o aumento nas distâncias interpopulacionais pode reduzir o fluxo gênico diretamente, enquanto as 
espécies dispersadas e polinizadas por animais esta redução é indireta e está associada aos efeitos da fragmentação sobre os animais (Young et al., 1996).

Apesar de ser considerada uma única população panmítica, como foi visto acima, levando em consideração as pequenas distâncias entre os fragmentos, avalia-se que o valor do fluxo gênico encontrado para as populações de cambuí foi relativamente alto $\left(N_{m}=4,25\right)$, deste modo sugere-se que o valor deste fluxo gênico encontrado deva-se a dependência dos dispersores. Provavelmente estes dispersores podem voar de um fragmento a outro, as populações não estão distantes o suficiente, provavelmente, antes da fragmentação elas faziam parte de uma única população, e como a espécie tem crescimento muito lento e alta longevidade, os indivíduos jovens analisados são filhos de muitas plantas pré-fragmentação.

A matriz circundante dos fragmentos analisados é composta por áreas de pastagem, culturas agrícolas e outros fragmentos de floresta. A matriz pode influenciar o fluxo gênico entre os fragmentos. A população de Carapa guianensis (Dayanandan et al., 1999) localizadas em fragmentos circundados por áreas de pastagem ou com alto grau de perturbação antrópica, mostraram maior diferenciação genética do que aquelas áreas circundadas por uma matriz composta por áreas menos perturbadas ou por outros fragmentos. As árvores localizadas em fragmentos e pastagens, podem fornecer fluxo de pólen e sementes para as áreas vizinhas (Chase et al., 1996). Considerando a capacidade que alguns agentes dispersores e polinizadores tem de percorrer longas distâncias, essas árvores podem representar um corredor para o fluxo gênico entre os fragmentos, contribuindo para a manutenção da diversidade genética nos fragmentos (Chase et al., 1996).

Foi observado a existência de indivíduos de cambuí em áreas de pastagem e em outros fragmentos ao redor dos fragmentos em estudo, no entanto estudos detalhados sobre a dinâmica das populações poderiam dar mais informações sobre os efeitos da matriz circundante nos padrões de fluxo gênico em cambuí. 
O tamanho efetivo populacional desta espécie foi igual a 36,81 , ou seja, 92\% dos indivíduos amostrados. É importante conhecer a representatividade genética das amostras, por causa das atividades de coleta de sementes de plantas alógamas, pois segundo Vencovsky (1987) não adianta coletar muitas sementes de uma única planta, que não eqüivalerão as outras sementes colhidas de diferentes árvores.

Os resultados deste trabalho mostram que de certa forma a fragmentação pode conduzir a redução da diversidade genética nas populações de cambuí. Se não houver estratégias de conservação e o processo de fragmentação realizada pelo homem continuar em grandes proporções na região da Bacia do Rio Camanducaia, é provável que a diversidade genética presente nas populações fragmentadas de cambuí e em outras espécie com características e biologia semelhantes continuem a reduzir com o passar das gerações, ameaçando a persistência em gerações futuras. 


\section{CONCLUSÕES}

As principais conclusões deste trabalho a partir da análise da diversidade e estrutura genética utilizando marcadores isoenzimáticos foram:

- As populações dos fragmentos menores apresentaram menor variação genética, avaliada pela riqueza alélica, que as populações estudadas no fragmento controle.

- Alguns alelos encontrados em menor freqüência no fragmento controle tiveram suas freqüências reduzidas nos fragmentos menores, sendo que um alelo foi perdido nos fragmentos menores, provavelmente devido à redução do tamanho populacional durante a fragmentação e possivelmente devido à deriva genética após a fragmentação ou a amostragem realizada.

- A diversidade gênica de Nei (heterozigosidade esperada) não foi diferente para as quatro populações apesar de ter sido encontrado valores menores para os fragmentos menores.

- Pelo valor de $\hat{f}$ encontrado $(0,0864)$ conclui-se que estas populações estão tendo cruzamentos panmíticos, provavelmente devido estes indivíduos analisados pertencerem a primeira ou segunda geração após a fragmentação, e portanto provavelmente não havendo tempo de detectar 0 efeito dessa fragmentação no sistema de cruzamento desta espécie.

- As quatro populações apresentaram pequena diferenciação genética entre elas $\left(\hat{\boldsymbol{\theta}}_{p}=0,0555\right)$ e número estimado de migrantes relativamente alto $\left(N_{m}=\right.$ $4,25)$. 
- Apesar de ter sido intenso o processo de fragmentação dos ecossistemas florestais da Serra da Mantiqueira, observa-se que para a espécie estudada, este processo ainda não afetou significativamente a diversidade e estrutura genética de indivíduos pré-reprodutivos. 
ANEXOS 
Anexo A. Composição, em quantidades para o volume de $1 \mathrm{~L}$ e preparo dos sistemas-tampão gel/eletrodo de morfolina e lítio, segundo Alfenas (1998).

\begin{tabular}{cccc}
\hline \hline Sistema & Tampão do gel & Tampão do eletrodo & Condições de corrida \\
\hline \hline & & & \\
& $\mathrm{H}_{3} \mathrm{C}$ itr1 $\mathrm{H}_{2} \mathrm{O} 8,4 \mathrm{~g}$ & o mesmo do gel & $50 \mathrm{~mA}$ \\
$\mathrm{pH} 6,5$ & &
\end{tabular}

Procedimento: Dissolva o ácido cítrico e titule com N-(3-aminopropil) morfolina. Dilua para seu uso a 1:20

\begin{tabular}{llcr} 
18 & 6,20g & $\mathrm{LiOH} \mathrm{1M \quad 2g}$ & $70 \mathrm{~mA}$ \\
$\mathrm{H}_{3} \mathrm{Citr} \quad 1,46 \mathrm{~g}$ & $\mathrm{H}_{3} \mathrm{BO}_{3} \quad 11,89 \mathrm{~g}$ & \\
\multicolumn{2}{c}{$\mathrm{pH} 8,0$} & $\mathrm{pH} 8,0$
\end{tabular}

Procedimento: Para seu uso, misture 10 partes do tampão do gel com uma parte do tampão do eletrodo 
Anexo B. Sistemas isoenzimáticos testados:

Aconitato hidratase (ACO - EC 4.2.1.3)

Álcool desidrogenase (ADH - EC 1.1.1.1)

Aldolase (ALD - EC 4.1.2.13)

Amino aspartato transferase (AAT - EC 2.6.1.1)

Diaforase (DIA - EC1.8.1.4)

Enzima málica (ME - EC 1.1.1.40)

Fosfatase ácida (ACP - EC 3.1.3.2)

Fosfoglucomutase (PGM - EC 2.7.5.1)

Fosfoglucose isomerase (PGI - EC 5.3.1.9)

6-Fosfogluconato desidrogenase (6PGDH - EC 1.1.1.44)

a-Glicerofosfato desidrogenase (a-GPDH - EC 1.1.1.8)

Glucose-6-fosfato desidrogenase (G6PDH - EC 1.1.1.49)

Glutamato desidrogenase (GDH - EC 1.4.1.3)

Hexocinase (HK - EC 2.7.1.1)

Isocitrato desidrogenase (IDH - EC 1.1.1.42)

Leucina aminopeptidase (LAP - EC 3.4.11.1)

Malato desidrogenase (MDH - EC 1.1.1.37)

Manose-6-fosfato isomerase (MPI - EC 5.3.1.8)

Sorbitol desidrogenase (SDH - EC 1.1.1.14)

Triose-fosfato isomerase (TPI - EC 5.3.1.1)

Uridina difosfoglucose pirofosforilase (UGPP - EC 2.7.7.9)

Xiquimato desidrogenase (SKDH - EC 1.1.1.25) 
Anexo C. Protocolo para revelação dos sistemas enzimáticos utilizados:

1) Glucose-6-fosfato desidrogenase (G6PDH - EC 1.1.1.49) - modificado a partir de Soltis et al. (1983):

Glucose-6-fosfato

$0.02 \mathrm{~g}$

$\mathrm{NADP}^{+}, \mathrm{Na} 2$

$1 \mathrm{ml}$

MTT

$1 \mathrm{ml}$

PMS

$1 \mathrm{ml}$

$\mathrm{MgCl}_{2}$

$1 \mathrm{ml}$

Tris- $\mathrm{HCl} 0,2 \mathrm{M}, \mathrm{pH} 8,0$

$50 \mathrm{ml}$

Procedimento: Os reagentes eram diluídos no tampão e os géis imersos nesta solução e incubados no escuro por 40 minutos a $35^{\circ} \mathrm{C}$.

2) Fosfogluco isomerase (PGI - EC 5.3.1.9) - modificado a partir de Soltis et al. (1983):

Frutose-6-fosfato, $\mathrm{Na} 2$

$0.037 g$

$\mathrm{NADP}^{+}, \mathrm{Na} 2$

$1 \mathrm{ml}$

MTT

$1 \mathrm{ml}$

PMS

$1 \mathrm{ml}$

$\mathrm{MgCl}_{2}$

$1 \mathrm{ml}$

Tris- $\mathrm{HCl} 0,1 \mathrm{M}, \mathrm{pH} 8,0$

$50 \mathrm{ml}$

G6PDH

$20 \mu \mathrm{l}$

Procedimento: Os reagentes eram diluídos no tampão e os géis imersos nesta solução e incubados no escuro por 40 minutos a $35^{\circ} \mathrm{C}$. 
Anexo C. Protocolo para revelação dos sistemas enzimáticos utilizados:

3) Isocitrato desidrogenase (IDH - EC 1.1.1.42) - modificado a partir de Soltis et al. (1983):

DL-ácido isocítrico, Na3

$0.02 \mathrm{~g}$

$\mathrm{NADP}^{+}, \mathrm{Na} 2$

$1 \mathrm{ml}$

$\mathrm{MTT}$

$1 \mathrm{ml}$

PMS

$1 \mathrm{ml}$

$\mathrm{MgCl}_{2}$

$1 \mathrm{ml}$

Tris- $\mathrm{HCl} 0,1 \mathrm{M}, \mathrm{pH} 8,0$

$50 \mathrm{ml}$

Procedimento: Os reagentes eram diluídos no tampão e os géis imersos nesta solução e incubados no escuro por 40 minutos a $35^{\circ} \mathrm{C}$.

4) Leucina Aminopeptidase (LAP - EC 3.4.11.1) - modificado a partir de Soltis et al. (1983):

Solução A: Tris maleato $0,2 \mathrm{M}, \mathrm{pH} 3,3$ :

Tris

Ácido maléico

Água destilada
$24,2 \mathrm{~g}$

$23,2 \mathrm{~g}$

$1000 \mathrm{ml}$

Solução B: Hidróxido de Sódio 0,2 M

Foi misturado $50 \mathrm{ml}$ de A e $20 \mathrm{ml}$ de B e completado com água para $200 \mathrm{ml}$ resultando em $\mathrm{pH} 6,0$.

L-leucina-ß-naftilamida- $\mathrm{HCl}$

$0,005 \mathrm{~g}$

Fast black $\mathrm{K}$ salt

$0,01 \mathrm{~g}$

Mistura de A+B

$70 \mathrm{ml}$

Água destilada

$30 \mathrm{ml}$

Procedimento: Os reagentes eram diluídos no tampão e os géis imersos nesta solução e incubados no escuro por 1 hora a $35^{\circ} \mathrm{C}$. 
Anexo C. Protocolo para revelação dos sistemas enzimáticos utilizados:

5) Uridina-5-difosfoglucose pirofosforilase (UGPP - EC 2.7.7.9) (ágar)

Uridina-5-difosfoglucose

$0,025 \mathrm{~g}$

Pirofosfato, $\mathrm{Na} 2$

$0,025 \mathrm{~g}$

Glucose-1,6-difosfato

$1 \mathrm{ml}$

NAD

$1 \mathrm{ml}$

$\mathrm{MTT}$

$1 \mathrm{ml}$

PMS

$1 \mathrm{ml}$

$\mathrm{MgCl}_{2}$

$1 \mathrm{ml}$

G6PDH

$10 \mu \mathrm{l}$

Fosfoglucomutase

$90 \mu \mathrm{l}$

Tris- $\mathrm{HCl} 0,1 \mathrm{M}, \mathrm{pH} 8,0$

$25 \mathrm{ml}$

Procedimento: Os reagentes eram diluídos no tampão com ágar morno e vertido em cima dos géis, e incubados no escuro por 30 minutos a $35^{\circ} \mathrm{C}$.

6) Triosefosfato isomerase (TPI - EC5.3.1.1) (ágar) - modificado a partir de Soltis et al. (1983):

Diidroxiacetona-fosfato (DHAP.Li)

$500 \mu \mathrm{l}$

EDTA

$0,019 \mathrm{~g}$

Ácido arsênico

$2 \mathrm{ml}$

NAD

$1 \mathrm{ml}$

MTT

$1 \mathrm{ml}$

PMS

$1 \mathrm{ml}$

Tris- $\mathrm{HCl} 0,1 \mathrm{M}, \mathrm{pH} 8,0$

$25 \mathrm{ml}$

G3PDH

$0,004 \mathrm{~g}$

Procedimento: Os reagentes eram diluídos no tampão com ágar morno e vertido em cima dos géis, e incubados no escuro por 40 minutos a $35^{\circ} \mathrm{C}$. 
Anexo C. Protocolo para revelação dos sistemas enzimáticos utilizados:

7) Aspartato aminotransferase (AAT - EC 2.6.1.1) - modificado a partir de Soltis et al. (1983):

Solução substrato AAT pH7,4 (aferir com $\mathrm{NaOH}$ ou HCl) $\quad 50 \mathrm{ml}$

$\begin{array}{ll}\text { Ácido Ketoglutárico } & 0,018 \mathrm{~g} \\ \text { Ácido L-aspártico } & 0.067 \mathrm{~g} \\ \text { PVP-40 } & 0,25 \mathrm{~g} \\ \text { EDTA } & 0,025 \mathrm{~g} \\ \text { Fosfato de sódio bibásico } & 0,71 \mathrm{~g}\end{array}$

Fast Blue BB salt

$0,05 \mathrm{~g}$

Procedimento: A solução substrato de AAT deve ser sempre fresca. 


\section{REFERÊNCIAS BIBLIOGRÁFICAS}

AGUARI Ações sociais para a preservação de fragmentos florestais na bacia do Rio Camanducaia. Camanducaia: PROBIO, MMA, 2001. 40p. (Relatório Técnico Subprojeto Social).

ALDRICH, P. R.; HAMRICK, J. L.; CHAVARRIAGA, P.; et al. Microsatellite analysis of demographic genetic structure in fragmented populations of the tropical tree Symphonia globulifera. Molecular Ecology, v.7, p.933-944, 1998.

ALFENAS, A C.; PETERS, I.; BRUNE, W. et al. Eletroforese de proteínas e isoenzimas de fungos e essências florestais. Viçosa: SIF, 1991. 242p.

ALFENAS, A. C.; BRUNE, W.; OLIVEIRA, J. R.; et al. Eletroforese de isoenzimas e proteínas afins: fundamentos e aplicações em plantas e microrganismos. Viçosa: UFV, 1998. p.85-114.

AMARAL, W. Characterzation, evaluation and conservation of forest genetic resources: the potential and limitations of new biotechnology tools. In: SHAANKER, R.; GANESHAIA, K. N.; BAWA, K. S. (Ed.) Forest genetic resources: status, threats and conservation strategies. New YorK: Science Publications, 2001. cap. 20. 
AYOADE, J. O. Introdução a climatologia para os trópicos. 5. ed. Rio de Janeiro: Bertrand Brasil, 1998. 332p.

BARRET, S.C.H.; KOHN, J. R. Genetic and evolutionary consequences of small populations size in plants: implications for conservation. In: FALK, D.A.; HOLSINGER, K.E. (Ed.) Genetic and conservation of rare plants. New York: Oxford University Press, 1991. p.3-30.

BARTON, N. H.; SLATKIN, M. A quasi-equilibrium theory of the distribution of rare alleles in a subdivided population. Heredity, v.56, p.409-415, 1986.

BLACK, W. C. BIOSYS-2: 1997 atualização do BIOSYS-1, a computer program for the analysis of allelic variation in population genetics and biochemical systematics; release 1.7. Illinois: Illinois History Survey, 1989.

BROWN, A. H. D.; WEIR, B. S Measuring genetic variability in plant populations. In: TANKSLEY, S. D.; ORTON, T. J. (Ed.) Isozymes in plant genetics and breeding. Amsterdam: Elsevier, 1983. Pt. A, p.219-239.

CHASE, M. R.; BOSHIER, D. H.; BAWA, K. S. Population genetics of Cordia alliodora (Boraginaceae), a neotropical tree. 1. Genetic variation in natural populations. American Journal of Botany, v.82, p.468-475, 1996.

COATES D. J.; HAMLEY, V. L. Genetic divergence and the mating system in the endangered and geographically restricted species, Lambertia orbifolia gardner (Proteaceae). Heredity, v.83, p.418-427, 1999. 
COLlEVATTI, R. G.; GRATTAPAGLIA, D.; HAY, J. D. Population genetic structure of the endangered tropical tree species Caryocar brasiliense, based on variability at microsatellite loci. Molecular Ecology, v.10, p.349356, 2001.

CONSÓRCIO FIGUEIREDO FERRAZ. Programa de investimentos para proteção e aproveitamento dos recursos hídricos das bacias dos Rios Piracicaba, Capivari e Jundiaí. São Paulo, 1999. 77p.

DAYANANDAN, S.; DOLE, J.; BAWA, K.; KESSELI, R. Population structure delineated with microsatellite markers in fragmented populations of a tropical tree, Carapa guianensis (Meliaceae). Molecular Ecology, v.8, p.1585-1592, 1999.

EGUIARTE, L.E.; PÉREZ-NASSER, N.; PIÑERO, D. Genetic structure, outcrossing rate, and heterosis in Astrocaryum mexicanum (tropical palm): implications for evolution and conservation. Heredity, v.69, p.217-228, 1992.

FALCONER, D. S. Introduction to quantitative genetics. Longman: Harlow, 1996.

FORÉ, S. A.; HICKEY, R. J.; VANKAT, J. L. et al. Genetic structure after forest fragmentation: na landscape ecology perspective on Acer saccharum. Canadian Journal of Botany, v.70, p.165-168, 1992.

FRANÇA, G. S. Composição florística e estrutura do componente arbóreo de uma Floresta Montana do sul de Minas Gerais, Brasil. Belo Horizonte, 2002. 61p. Dissertação (M. S.) - Universidade Federal de Minas Gerais. 
FRANCESCHINELLI, E. V. Efeito da Fragmentação de Habitats na Diversidade Genética de Espécies Arbóreas Presentes na APA Fernão Dias (MG). Belo Horizonte: PROBIO, MMA, 2001. 26p. (Projeto de Pesquisa).

FRANKEL, O. H.; SOULÉ, M. E. Conservation and evolution. Cambridge: University Press, 1981.

FRANKHAM, R. Relationships of genetic variation to population size in Wildlife. Conservation Biology, v.10, p.1500-1508, 1996.

FUNDAÇÃO BIODIVERSITAS. Biodiversidade em Minas Gerais: um atlas para sua conservação. Belo Horizonte, 1998. 94 p.

FUNDAÇÃO SOS MATA ATLÂNTICA. Atlas da evolução do remanescentes florestais e ecossistemas no domínio da Mata Atlântica no período de 1990-1995. São Paulo, SOS Mata Atlântica, 1998.

GAYER, P. Annuario de Jaguary. Camanducaia, 1924.

GONZÁLEZ-ASTORGA, J.; NÚÑEZ-FARFÁN, J. Effect of habitat fragmentation on the genetic structure of the narrow endemic Brongniartia vazquezii. Evolution Ecology Research, v.3, p.861-872, 2001.

GRANT, V. Gene flow and the homogeneity of species populations. Biologisches Zentralblatt, v.99, p.157-169, 1980.

HALL, P.; ORREL, L. C.; BAWA, K. S. Genetic diversity and mating system in a tropical tree, Carapa guianensis (Meliaceae). American Journal of Botany, v.81, p.1104-1111, 1994. 
HAMRICK, J. L. The distribuition of genetic variation within and among natural plant populations. In: SHONEWALD-COX, C. M.; CHAMBERS, S. M.; MACBRYDE, B.; et al. (Ed.) Genetics and conservation: A reference for managing wild animal and plant populations. Melo Park: Benjamin Cummings, 1983. p.335-348.

HAMRICK, J. L.; GODT, M. J. W. Allozyme diversity in plant species. In: BROWN, A. H. D.; CLEGG, M. T.; KAHLER, A. L. E.; et al. (Ed.) Plant population genetics, breeding and genetic resources. Sunderland: Sinauer, 1989. p. 43-63.

HAMRICK, J. L.; GODT, M. J. W. Allozyme diversity in plant species. In: BROWN, A. H. D.; CLEGG, M. T.; KAHLER, A. L. et al. (Ed.). Plant population genetics, breeding and genetic resources. Sunderland: Sinauer Associates, 1990. p.145-162.

HAMRICK, J. L.; LOVELESS, M. D. The genetic structure of tropical tree populations: associations with reproductive biology. In: BOCK, J. E.; LINHART, Y. B. (Ed.) Evolutionary ecology of plants westview. Colo: Press Boulder, 1989, p. 129-146.

HAMRICK, J. L.; MURAWSKI, D. A. Levels of allozyme diversity in populations of uncommon neotropical tree species. Journal Tropical Ecology, v.7, p.385-399, 1991.

HAMRICK, J. L.; NASON, J. D. Gene Flow in Forest Trees. In: YOUNG, A.; BOSHIER, D.; BOYLE, T. (Ed.) Forest conservation genetics: principles and practice. Melbourne: CSIRO, 2000. cap. 6, p.81-90. 
HARRIT, M. M. Ecology and genetic variation of four hardwoods of Brazil's atlantic forest region. Raleigh, 1991. 204p. Thesis (PhD) - North Carolina State University.

HARTL, D. L.; CLARK, A. G. Principles of population genetics. 3. ed. Sunderland: Sinauer Associates, 1997.

HEYWOOD, V. H.; STUART, S. N. Species extinctions in tropical forest. In: WHITMORE, T. C.; SAYER, J. A. (Ed.) Tropical deforestation and species extintion. New York: Chapman \& Hall, 1994. p.91-114.

IBITU CONSULTORIA AMBIENTAL Plano de gestão ambiental da APA Fernão Dias. Belo Horizonte. 1998. v.1: Departamento de Estradas de Rodagem-MG (DER-MG).

LOVELLESS, M. D. Isozyme variation in tropical trees: patterns of genetic organization. New Forestry, v.6, p.67-94, 1992.

MACEDO, A. C. Revegetacão, matas ciliares e de proteção ambiental. São Paulo: Fundação Florestal, 1993. 27p.

MEFFE, G. K.; CARROL, C. R. Principles of conservation biology. Sunderland: Sinauer Associates, 1994.

MEIRELLES, S. Mantiqueira, a riqueza nativa da Mata Atlântica. Ecologia e Desenvolvimento, v.9, p.20-27, 1991. 
MENDES JÚNIOR, L. O.; ANTONIAZZI, M.; VIEIRA, M. C. W.; SUCEMIHL, P. Relatório Mantiqueira. São Paulo: Frente em Defesa da Mantiqueira, $1991.54 \mathrm{p}$.

MILLER, M. P. TFPGA: tools for populations genetics analyses 1.3: a windows program for the analysis of allozime and molecular population genetic data. Computer software distributed by author. 1997.

MILLIGAN, B. G.; LEEBENS-MACK, J; STRAND, A. E. Conservation genetics: beyond the maintenance of marker diversity. Molecular Ecology, v.3, p.423-435, 1994.

MORAES, M. L. T. Variabilidade genética por isoenzimas e caracteres quantitativos em duas populações naturais de Myracroduon urundeuva F.F. \& M.F. Allemãao - ANACARDIACEAE (Syn: Astronium urundeuva FR Allemão Engle). Piracicaba, 1992. 153p. Tese (Doutorado) - Escola Superior de Agricultura "Luiz de Queiroz", Universidade de São Paulo.

MORAES, P. L.; MONTEIRO, R.; VENCOVSKY, R. Conservação genética de populações de Cryptocaria moschata Nees (Lauraceae) na Mata Atlântica do estado de São Paulo. Revista Brasileira de Botânica, v.22, p.237-248, out. 1999. n.2 (suplemento).

MUONA, O. Population genetics in forest tree improvement. In: BROWN, A. H. D.; CLEGG, M. T.; KHALER, A. L.; et al. (Ed.). Plant population genetics, breeding and genetic resources. Sunderland: Sinauer, 1990. p.282-298. 
NASON, J. D.; ALDRICH, P.R.; HAMRICK, J. L. Dispersal and the dynamics of genetic structure in fragmented tropical tree populations. In: LAURENCE, W. F. E.; BIERREGAARD JR., R. O. (Ed.) Tropical forest remnants: ecology, management, and conservation of fragmented communities. Chicago: University of Chicago Press, 1997. p.304-320.

NEI, M. Analysis of gene diversity in subdivided populations. Proceedings of the National Academic of Science of the United States of America, v.70, n.12, p.3321-3323, 1973.

$\mathrm{NEI}, \mathrm{M}$. Estimation of average heterozygosity and genetic distance from a small number of individuals. Genetics, v.89, n.3, p.583-590, 1978.

NEWBURY, H. J.; FORD-LLOYD, B. V. The use of RAPD for assessing variation in plants. Plant Growth Regulator, v.12, p.43-51, 1993.

O'MALLEY, D. M.; WHEELER, N. C.; GURIES, R. P. A manual for starch gel electrophoresis. Madison: University of Wisconsin Press, 1980.

OUBERG, N. J.; TREUREN, R.; VAN DAMME, J. M. M. The significance of genetic erosion in the process of extinction II. Morphological variation and fitness components in populations of varying size of Salvia pratensis L. and Scabiosa columbaria L. Oecologia, v.86, p.359-367, 1991.

PARKER, P. G.; SNOW, A. A.; SCHUG, M. D.; et al. What molecules can tell us about populations. Choosing and using a molecular marker. Ecology, v.79, n.2, p.361-382, 1998. 
PINTO, L. R.; VIEIRA, M. L. C.; SOUZA, A. P. et al. Isoenzimas e microssatélites em plantas. Biotecnologia Ciência \& Desenvolvimento, n.20, p.16-19, 2001.

RIBEIR0, R. A. Efeitos da fragmentação de habitats na estrutura genética de Dalbergia nigra (jacarandá-da-Bahia): uma espécie ameaçada da Mata Atlântica, Belo Horizonte, 2002. 57p. Dissertação (M. S.) - Universidade Federal de Minas Gerais.

ROBINSON, I. P. Aloenzima na genética de populações de plantas. In: ALFENAS, A C. (Ed.) Eletroforese de isoenzimas e proteínas afins: fundamentos e aplicações em plantas e microrganismos. Viçosa: Editora UFV, 1998. cap. 7, p.329-380.

ROUTLEY M. B.; MAVRAGANIS, K.; ECKERT, C. G. Effect of population size on the mating system in a self-compatible, autogamous plant, Aquilegia canadensis (Ranunculaceae). Heredity, v.82, p.518-528, 1999.

SANTOS. E. M. G. Ecologia da polinização, fluxo de pólen e taxa de cruzamento em Bauhinia forficata Link. (Caesalpinaceae). Piracicaba, 1994. 114p. Dissertação (Mestrado) - Escola Superior de Agricultura "Luiz de Queiroz", Universidade de São Paulo.

SAUNDERS, D. A.; HOBBS, R. J.; MARGULES, C. R. Biological consequences of ecosystem fragmentation: a review. Consevation Biology, v.5, p.18-32, 1991.

SEBRAE. Camanducaia: diagnóstico municipal. Belo Horizonte: SEBRAE$M G, 1997.78 p$. 
SOBRAL, M. Sinopse de Myrciaria (Myrtaceae). NAPAEA, v.9, p.13-41, 1993.

SOLTIS, D. E.; HAUFLER, C. H.; DARROW, D. C.; et al. Starch gel electrophoresis of ferns: a compilation of grinding buffers, gel and electrode buffers, and staining schedules. American Fern Journal, v.73, p.9-27, 1983.

SUN, M Effects of population size, mating system, and evolutionary origin on genetic diversity in Spiranthes sinensis and $S$. hongkongensis. Conservation Biology, v.10, p.785-795, 1996.

TAGGART, J. B.; McNALLY, S. F.; SHARP, P. M. Genetic variability and differentiation among founder populations of the pitcher plant (Sarracenia purpurea L.) in Ireland. Heredity, v.64, p.117-183, 1990.

VÁRZEA, A. Relevo do Brasil. Revista Brasileira de Geografia, v. 4, p.97130, 1942.

VENCOVSKY, R. Biometrical Approaches for molecular markers: estimation of effective population size. In: (International Workshop on Agricultural Biotechnology), Piracicaba: ESALQ, USP, 1997. Proceedings. p.21-22.

VENCOVSKY, R. Tamanho efetivo populacional na coleta e preservação de germoplasmas de espécies alógamas. IPEF, v.35. 1987.

VIANA, V. M. Biologia e manejo de fragmentos florestais. In: (Congresso Florestal Brasileiro), 6, Campos do Jordão, 1990. São Paulo: SBS/SBEF, 1990. v.1, p.113-118. 
VIANA, V.M. Conservação da biodiversidade de fragmentos florestais tropicais em paisagens intensivamente cultivadas. In: CONFERÊNCIA INTERNACIONAL; "ON COMMON AROUND: INTERDICIPLINARY APROACHES BIODIVERSITY AND LAND USE DINAMICS IN THE WORLD", Belo Horizonte,1995. Anais. Belo Horizonte: FAPEMIG, 1995. p. 324-333.

WEIR, B. S. Genetic data analysis: methods for discrete populations genetic data. Sunderland: Sinauer Associates, 1990. 377p.

WEIR, B. S.; COCKERHAM, C. C. Estimating F-statistics for the analysis of population structure. Evolution, v.38, p.1358-1370, 1984.

WENDEL, J. F.; WEEDEN, N. F. Visualization and interpretation of plant isozymes. In: SOLTIS, D. E. E.; SOLTIS, P. S. (Ed.). Isozymes in plant biology. Portland: Discorides Press, 1989. p.5-45.

WHITE, G. M.; BOSHIER, D. H.; POWELL, W. Genetic variation within a fragmented population so Swietenia humilis Zucc. Molecular Ecology, v.8, p.1899-1909, 1999.

WRIGHT, S. Variability within and among natural Populations: Evolution and the Genetics of populations. Chicago: University of Chicago Press, 1978. v.4, 15p.

WRIGHT, S. Isolation by distance. Genetics, v.28, p.114-138, 1943.

WRIGHT, S. The interpretation of population structure by F-statistics with special regard to systems of mating. Evolution, v.19, p.395-420, 1965. 
YOUNG, A. G.; MERRIAN, H. G.; WARWICK, S. I. The effects of forest fragmentation on genetic variation in Acer saccharum Marsh. (sugar maple) populations. Heredity, v.71, p.277-289, 1993.

YOUNG, A.; BOYLE, T.; BROWN, T. The population genetic consequences of habitats fragmentation for plants. Tree, v.11, n.10, p.413-418, 1996. 